Nova Southeastern University

2014

\title{
Information System Security Commitment: A Study of External Influences on Senior Management
}

Kevin Andrew Barton

Nova Southeastern University, kb149@nova.edu

This document is a product of extensive research conducted at the Nova Southeastern University College of Engineering and Computing. For more information on research and degree programs at the NSU College of Engineering and Computing, please click here.

Follow this and additional works at: https://nsuworks.nova.edu/gscis_etd

Part of the Information Security Commons

\section{Share Feedback About This Item}

\section{NSUWorks Citation}

Kevin Andrew Barton. 2014. Information System Security Commitment: A Study of External Influences on Senior Management. Doctoral dissertation. Nova Southeastern University. Retrieved from NSUWorks, Graduate School of Computer and Information Sciences. (19)

https://nsuworks.nova.edu/gscis_etd/19. 


\title{
Information System Security Commitment: A Study of External Influences on Senior Management
}

\author{
by
}

Kevin Andrew Barton

A dissertation submitted in partial fulfillment of the requirements for the degree of Doctor of Philosophy

in

Information Systems with Concentration in Information Security

Graduate School of Computer and Information Sciences Nova Southeastern University 
Approval Page

Intentionally Left Blank 
An Abstract of a Dissertation Submitted to Nova Southeastern University

In Partial Fulfillment of the Requirements for the degree of Doctor of Philosophy

\title{
Information System Security Commitment: A Study of External Influences on Senior Management
}

\author{
by
}

Kevin A. Barton

November 2014

This dissertation investigated how senior management is motivated to commit to information system security (ISS). Research shows senior management participation is critical to successful ISS, but has not explained how senior managers are motivated to participate in ISS. Information systems research shows pressures external to the organization have greater influence on senior managers than internal pressures. However, research has not fully examined how external pressures motivate senior management participation in ISS. This study addressed that gap by examining how external pressures motivate senior management participation in ISS through the lens of neo-institutional theory. The research design was survey research. Data collection was through an online survey, and PLS was used for data analysis. Sample size was 167 from a study population of small- and medium-sized organizations in a mix of industries in the south-central United States. Results supported three of six hypotheses. Mimetic mechanisms were found to influence senior management belief in ISS, and senior management belief in ISS was found to increase senior management participation in ISS. Greater senior management participation in ISS led to greater ISS assimilation in organizations. Three hypotheses were not supported. Correlation was not found between normative influences and senior management belief, normative influences and senior management participation, and coercive influences and senior management participation. Limitations with the study included a high occurrence of weak effect sizes on relationships within the model and heterogeneity based on industry, organization size, and regulatory requirements in the sample. This study contributes to ISS research by providing a theoretical model to explain how external influences contribute to senior management belief and participation in ISS, and ultimately ISS assimilation in organizations. Empirical evidence supports the mediating role by senior management between external influences and ISS assimilation. The findings also suggest some limitations that may exist with survey research in this area. This study benefits practitioners in three ways. First, it reinforces the argument that senior management support is critical to ISS success. Second, it extends understanding of senior management's role with ISS by explaining how IS and ISS management might nurture senior management belief and participation in ISS through industry groups and business partnerships. Third, the results inform government regulators and industry groups how they can supplement regulatory pressures with educational and awareness campaigns targeted at senior management to improve senior management commitment to ISS. 


\section{Acknowledgements}

From the beginning, a completed dissertation was the goal, but the real value was in the process, not the product. The dissertation demonstrates the ability of a researcher to complete a significant study, but only after the process provides the skills in conceiving and justifying a research idea, designing a study, collecting and analyzing the data, and finally reporting the results. The process was rewarding in its own right.

I sincerely thank my advisor and committee chairperson, Dr. Gurvirender Tejay, for his direction, guidance, and focus. Dr. Tejay's steady and consistent mentorship gave me the confidence to follow a productive and purposeful path to completion.

Committee members Dr. Steve Terrell and Dr. Michael Lane provided valuable support through the dissertation process, and created an environment that fostered learning and development. Your insight pushed me to learn beyond where I had set my own limits.

I am especially grateful to my wife, Shirley, who encouraged and motivated me, while remaining patient and supporting as I hit the inevitable obstacles. You helped me strike the balance between steady progress and unproductive, wasted effort.

\section{Publications from this Research}

Tejay, G. P. S., \& Barton, K. A. (2013). Information System Security Commitment: A Pilot Study of External Influences on Senior Management. 2013 46th Hawaii International Conference on System Sciences, 3028-3037. doi:10.1109/HICSS.2013.273 


\section{Table of Contents}
Abstract iii
List of Tables vii
List of Figures viii

\section{Chapters}

\section{Introduction 1}

Introduction 1

Problem Statement and Research Argument 2

Definitions 3

Summary 7

\section{2. $\quad$ Review of Literature 8}

Introduction 8

Senior Management Support for ISS 8

ISS Management 12

Employee Compliance with ISS Policy and Controls 14

Security Awareness and Training 17

Security Culture 19

Senior Management Commitment to ISS 21

Summary 23

3. Research Methodology 25

Introduction 25

Epistemology and Research Method 25

Research Model 26

Research Design 32

Data Collection 34

Instrument Development 37

Summary 42

\section{4. $\quad$ Results 43}

Introduction 43

Data Analysis 43

Findings 50

Summary 61

5. Conclusions, Implications, Recommendations, and Summary 63

Introduction 63

Conclusions 63

Contributions to Research and Practice 65

Limitations and Delimitations 68 
Recommendations 69

Summary 72

Appendices

A. Data Collection Instrument 74

B. Participant Recruitment Letter 77

C. Participant Instructions for Managers 79

D. Participant Instructions for Employees 81

\section{References 83}




\section{List of Tables}

\section{Tables}

2.1 IS Managers' Ranking of Information Systems Security Concerns 10

3.1 Definitions, Measurement Items, and Supporting Literature for Exogenous Constructs 40

3.2 Definitions, Measurement Items, and Supporting Literature for Endogenous Constructs 41

4.1 Data Analysis Criteria 48

4.2 Industry Distribution 51

4.3 Number of Employees Distribution 52

4.4 Industries Subject to Information Security Regulation Distribution - Estimated by Researcher 53

4.5 Industries Subject to Information Security Regulation Distribution - Reported by Participants 53

4.6 Demographic Factors for Heterogeneity Tests 53

4.7 Normalized Cross-Loadings 55

4.8 Correlations among Major Constructs 56

4.9 Percent of Variance from Multiple Methods Factor Analysis 58

4.10 Multi-Group Analysis Results 59

4.11 Effect Size of Independent Constructs on Dependent Constructs 60

4.12 Summary of Key Statistical Results and Conclusions of Hypothesis Testing 61 


\section{List of Figures}

\section{Figures}

3.1 Neo-Institutional Theory by DiMaggio and Powell (1983) 27

3.2 Research Model 28

3.3 Constructs 38

4.1 PLS Analysis of Results 57 


\section{Chapter 1}

\section{Introduction}

\subsection{Introduction}

Senior management commitment is important to achieving effective information system security (ISS) in organizations (Boss, Kirsch, Angermeier, Shingler, \& Boss, 2009; Bulgurcu, Cavusoglu, \& Benbasat, 2010a; Da Veiga \& Eloff, 2007; Hu, Hart, \& Cooke, 2007; McFadzean, Ezingeard, \& Birchall, 2006). Although senior management commitment does not guarantee effective operational security, it is a prerequisite for effective development, implementation, and compliance with ISS controls (Boss et al., 2009; Bulgurcu et al., 2010a; Hu et al., 2007; McFadzean et al., 2006). Compliance increases the effectiveness of ISS controls (Herath \& Rao, 2009b). When correctly implemented, common ISS controls reduce risk to information systems and organizations (Harrison \& White, 2010). Therefore, organizations can reduce risk to information through effective ISS (Harrison \& White, 2010; McFadzean et al., 2006). Senior management commitment is also critical to organizational change (Dutton, Ashford, O’Neill, \& Lawrence, 2001; Dutton \& Ashford, 1993). It follows that senior management commitment to ISS can drive organizational change that reduces security risk to information systems and the organization.

Senior managers often lack commitment to or sufficient awareness of ISS (Chang \& Ho, 2006; Hsu, 2009; Hu et al., 2007; Smith, Winchester, Bunker, \& Jamieson, 2010), but can be motivated to support ISS by internal or external influences (Hu et al., 2007). 
Internal influences are less effective at motivating senior management, while external influences have a major impact on senior management (Hsu, 2009; Hu et al., 2007; Smith et al., 2010). However, there is limited empirical research examining how senior management is motivated to commit to ISS in their organizations.

IS and ISS research show that not only is senior management a dominant driver for organizational behavior (Enns, Huff, \& Higgins, 2003; Hu et al., 2007; Lee \& Larsen, 2009), but senior managers are also the key human agents between organizations and the external environment (Liang, Saraf, Hu, \& Xue, 2007). Further, senior managers are motivated by different factors than employees regarding ISS (Johnson, 2009). Research shows external influences motivate senior management commitment to ISS more strongly than internal influences (Hsu, 2009; Hu et al., 2007; Smith et al., 2010). However, there is little empirical research that examines how senior managers are motivated by those external influences. The remainder of this chapter is organized in three sections. Section 1.2 explains the research problem and research argument. Section 1.3 defines keys terms, and Section 1.4 summarizes the chapter.

\subsection{Problem Statement and Research Argument}

This study investigated how external influences motivate senior management commitment to ISS by examining the mediating role of senior management between external influences and ISS assimilation. The justification for this research was that senior management commitment is a key factor for determining ISS success within organizations, yet there is insufficient understanding of the factors that motivate senior management to commit to ISS. Although ISS research has established that senior 
management commitment leads to effective development, implementation, and compliance with ISS controls (Boss et al., 2009; Bulgurcu et al., 2010a; Da Veiga \& Eloff, 2007; Hu et al., 2007; McFadzean et al., 2006), there is insufficient understanding about the factors that motivate senior management to commit to ISS (Johnson, 2009).

ISS controls reduce risk (Harrison \& White, 2010). Although some controls are automated or integrated into operations, many controls are more effective with employee compliance (Boss et al., 2009; Bulgurcu et al., 2010a; Hu et al., 2007; McFadzean et al., 2006). Senior management commitment to ISS improves employee compliance (Boss et al., 2009; Bulgurcu et al., 2010a; Hu et al., 2007). While senior management could be motivated to commit to ISS by either internal or external influences, research shows external influences have greater impact on senior management (Dutton et al., 2001; Dutton \& Ashford, 1993; Liang et al., 2007; Smith et al., 2010). Therefore, understanding how external influences motivate senior management participation in ISS is key to improving ISS in organizations (Holgate \& Hardy, 2012; Werlinger, Hawkey, \& Beznosov, 2009). Although ISS research has provided anecdotal evidence showing senior management responds to external influences (Allen, 2005; Holgate \& Hardy, 2012; Hsu, 2009; Hu et al., 2007; Patnayakuni \& Patnayakuni, 2014; Smith et al., 2010), there remains a gap in empirical research that examines how external influences motivate senior management participation in ISS.

\subsection{Definitions}

Assimilation occurs at the point when an innovation begins to be phased into an organization (Mignerat \& Rivard, 2009; Swanson \& Ramiller, 2004). Assimilation is 
defined as the extent to which a technology is diffused across an organization's work processes, and becomes routine in those processes (Chatterjee, Grewal, \& Sambamurthy, 2002; Liang et al., 2007; Purvis, Sambamurthy, \& Zmud, 2001). Assimilation is also considered the effective application of a technology to enable a business strategy (Armstrong \& Sambamurthy, 1999). For this study, ISS assimilation is the extent to which ISS is diffused across an organization's work processes, and becomes routine in those processes to ensure successful execution of an ISS strategy.

An Information system is sometimes defined as a group of assets, including hardware, software, data, people, and infrastructure (Sun, Srivastava, \& Mock, 2006). However, this definition assumes information systems are static systems and fails to distinguish between data and information. This research uses a definition for information systems that accounts for the transfer of knowledge: an information system is an aggregate of an organization's information handling activities at the technical, formal, and informal levels (Liebenau \& Backhouse, 1990). The technical level includes only the information technology component of an information system, but is often confused as being the information system itself (Dhillon \& Backhouse, 1994, 1996). The formal level includes the bureaucracy and rules for the use of information (Dhillon \& Backhouse, 1994, 1996). The informal level includes the organizational cultural levels where meanings are established, intentions understood, and beliefs are made, altered, or executed (Dhillon \& Backhouse, 1994, 1996).

Information system security has been defined as the "effective implementation of policies to ensure confidentiality, availability, and integrity of information and assets to protect from theft, tampering, manipulation, or corruption" (Smith \& Jamieson, 2006, p. 
24). This definition assumes risk to information primarily comes from human actors, and fails to fully account for other threat sources, such as natural or technical disasters. A second definition for ISS is the technical means, management controls, and management of behavior to protect an organization's information resources (Dhillon \& Torkzadeh, 2006). Although this definition accounts for a more complete set of information risks, it does not explain when an information system is considered protected. Protection implies all risk has been eliminated, but that state is unattainable. Anderson (2003) defines information security as, "a well-informed sense of assurance that information risks and controls are in balance" (p. 310). This definition conveys that management understands the risks, the degree to which those risks have been mitigated, and the residual risk is within an acceptable level (Anderson, 2003). This research defines information system security as a well-informed sense of assurance that risks to information resources are in balance with technical, administrative, and behavioral controls (Anderson, 2003; Dhillon \& Torkzadeh, 2006).

Senior management, top management, and top management teams are commonly used terms in management literature (Hambrick \& Mason, 1984; Hambrick, 1981; Nicholson, Schuler, \& Van de Ven, 1998), but a single definition is not widely accepted. Some management researchers draw a distinction between senior management and top management (Bourgeois, 1980), while others consider top management and senior management synonymous (Gallén, 2009). Top management teams or senior management are sometimes considered the group of executive-level officers (Covin, Slevin, \& Schultz, 1997; Hambrick, 1981), while other times they refer to both executive and non-executive directors (Glunk, Heijltjes, \& Olie, 2001; Maassen, 2002). When the top management 
team is considered to include both executive and non-executive directors, the executive directors are responsible for management and direction of the organization's day-to-day activities, while the non-executives perform a monitoring role on behalf of the owners and shareholders (Glunk et al., 2001; Maassen, 2002). Management research draws a distinction between senior managers and middle managers. Middle managers include second-tier executives that oversee functions within a strategic business unit (Judge \& Stahl, 1995; Westley, 1990; Wooldridge \& Floyd, 1990). This research defines senior management as the executive level directors who are responsible for the day-to-day activities and strategic direction of an organization, including the chief executive officer (CEO), other executive directors, and vice presidents who work closely with the CEO (Bowman \& Kakabadse, 1997; Colbert, Kristof-Brown, Bradley, \& Barrick, 2008; Hambrick \& Mason, 1984).

Liang et al. (2007) found senior management belief and senior management participation indicated the degree to which senior management would support an organizational initiative. The intensity of senior management support of an initiative can range from awareness to providing financing and resources to active participation (Kankanhalli, Teo, Tan, \& Wei, 2003). Similarly, management shows reduced commitment to ISS when they do not establish adequate policy, fail to set an example, make work demands inconsistent with security policy, or invest in security awareness and training (Puhakainen \& Siponen, 2010). Senior management commitment is defined as the degree to which senior management supports an organizational initiative (Liang et al., 2007). 
Isomorphism is a process that drives organizations to become more homogeneous over time, and is driven by three primary forces: coercive, mimetic, and normative mechanisms (DiMaggio \& Powell, 1983). Coercive mechanisms are defined as formal or informal pressures to adopt practices or structures an organization considers necessary to be viewed as legitimate in the culture or environment where they operate (DiMaggio \& Powell, 1983). Mimetic mechanisms are defined as the pressure to model an organization after another organization that is perceived as effective in the face of uncertainty or ambiguity (DiMaggio \& Powell, 1983). Normative mechanisms are defined as the professionalization of the workforce, primarily through similar education and participation in trade associations (DiMaggio \& Powell, 1983).

\subsection{Summary}

ISS research widely recognizes that senior management commitment is important to successful planning and implementation of ISS within organizations. However, very little research has examined the factors, or influences, that motivate senior management commitment to ISS. This dissertation addressed that gap by studying how influences external to organizations motivate senior management to commit to ISS. The remainder of this dissertation is organized in four chapters. Chapter 2 is a review of the relevant literature on ISS research. Chapter 3 describes the research methodology. Chapter 4 explains data analysis, the findings, and summarizes the results. Chapter 5 explains conclusions, contributions to research and practice, and recommendations from this study. 


\section{Chapter 2}

\section{Review of Literature}

\subsection{Introduction}

The literature review is organized in seven sections. Section 2.2 reviews literature on senior management support for ISS. Section 2.3 discusses research on ISS management. Section 2.4 reviews literature on employee compliance with ISS policy and controls. Section 2.5 examines research on security awareness and training. Section 2.6 looks at organizational security culture. Section 2.7 discusses extant research on motivating senior management to commit to ISS. Section 2.8 summarizes the chapter.

\subsection{Senior Management Support for ISS}

The value of senior management support to information systems (IS) and information technology (IT) has been studied since the beginning of IS/IT adoption in organizations (Doll, 1985; Garrity, 1963; Jarvenpaa \& Blake, 1991; Meador \& Keen, 1984; Vanlommel \& De Brabander, 1975). Early research on senior management support

for IS/IT followed two streams: participation and involvement (Jarvenpaa \& Blake, 1991). Participation is defined as the personal activities in IS/IT management, such as planning, development, and implementation of IS/IT (Jarvenpaa \& Blake, 1991). Involvement is senior management's psychological state that reflects the degree of importance senior management places on IS/IT (Jarvenpaa \& Blake, 1991). Although senior management 
participation and involvement contribute to greater IS/IT success in an organization, involvement is the more effective form of support (Jarvenpaa \& Blake, 1991).

Similarly, ISS researchers widely believe senior management commitment is important to achieving effective ISS in organizations (Boss et al., 2009; Bulgurcu et al., 2010a; Chai, Yap, \& Wang, 2011; Da Veiga \& Eloff, 2007; Holgate \& Hardy, 2012; Hu et al., 2007; Kankanhalli et al., 2003; McFadzean et al., 2006; Patnayakuni \& Patnayakuni, 2014; Werlinger et al., 2009). Hsu, Lee, \& Straub (2012) found senior management support to be a key factor in effective ISS assimilation in Korean organizations. ISS is achieved when ISS controls and ISS risk are in balance (Anderson, 2003). Senior management commitment is a prerequisite for effective development, implementation, and compliance with ISS controls (Boss et al., 2009; Bulgurcu et al., 2010a; Hu et al., 2007; McFadzean et al., 2006). Information sharing with business partners increases ISS complexity, further driving the demand for senior management commitment to ISS (Patnayakuni \& Patnayakuni, 2014).

Many studies about key issues for IS and ISS do not reflect senior management's views. A survey of the Society for Management Information Systems (SMIS) conducted in 1980 ranked the critical issues faced by management information systems (MIS) executives (Ball \& Harris, 1982). Two ISS related issues were identified: maintaining information privacy and MIS ethics (Ball \& Harris, 1982). The study claims to reflect the views of upper and top management, but the participants held middle management positions in MIS management, information resource management, systems development, and education and training (Ball \& Harris, 1982). Senior executives such as CEOs, COOs, or CFOs were not surveyed (Ball \& Harris, 1982). Just $27.7 \%$ of participants identified 
themselves as top management, while $51.7 \%$ were middle management, and the remainder were lower level personnel (Ball \& Harris, 1982). Similar studies have been repeated through the years (Brancheau, Janz, \& Wetherbe, 1996; Brancheau \& Wetherbe, 1987; Caudle, Gorr, \& Newcomer, 1991; Dickson, Leitheiser, Wetherbe, \& Nechis, 1984; Hartog \& Herbert, 1986). These studies consistently examine IS management's views, but fail to understand senior management's views of IS.

Senior and middle MIS managers' involvement with ISS has been surveyed multiple times over the years (Ball \& Harris, 1982; Brancheau et al., 1996; Brancheau \& Wetherbe, 1987; Caudle et al., 1991; Dickson et al., 1984; Hartog \& Herbert, 1986; Holgate \& Hardy, 2012). Although there is some variability, results from these studies have been reasonably consistent. Table 2.1 summarizes results from prior research. IS management ranking of ISS issues has been surveyed multiple times, but little research emphasis has focused on assessing senior management support of ISS (Kotulic \& Clark, 2004).

Table 2.1 IS Managers’ Ranking of Information System Security Concerns

\begin{tabular}{|c|c|c|}
\hline Study Population & Findings & Source \\
\hline Senior and middle IS managers & $\begin{array}{l}\text { Data security, information privacy, } \\
\text { and ethics ranked } 12 \text { th, } 14 \text { th, and } \\
17 \text { th, respectively }\end{array}$ & Ball \& Harris (1982) \\
\hline IS professionals and academics & Data security ranked 14 th & Dickson et al. (1984) \\
\hline IS managers from St. Louis area & Data security ranked 6th & Hartog \& Herbert (1986) \\
\hline $\begin{array}{l}\text { IS and non-IS executive } \\
\text { managers }\end{array}$ & Data security ranked 18th & Brancheau \& Wetherbe (1987) \\
\hline Government IS managers & $\begin{array}{l}\text { Data security ranked } 6 \text { th, data } \\
\text { integrity } 17 \text { th, and computer viruses } \\
31 \text { st }\end{array}$ & Caudle et al. (1991) \\
\hline Senior and middle IS managers & Data security not a major concern & Brancheau et al. (1996) \\
\hline
\end{tabular}


A limited number of studies have assessed senior management's view of key IS and ISS issues, but have not evaluated the factors that helped create those views or how senior management's views affected the rest of the organization. Moynihan (1990) considered views from three groups: senior managers, senior functional managers, and information technology managers. Senior managers were CEOs, senior functional managers were CEO's direct reports, and information technology managers were directors of information technology (Moynihan, 1990). Similarities and disparities were found between the three groups (Moynihan, 1990). Security was a low priority for information technology managers, but was not even a concern for senior managers or senior functional managers (Moynihan, 1990). Moynihan examined opinions of the three groups, but did not attempt to determine how those opinions were formed, or how the groups might have influenced each other. Watson (1990) studied how information system (IS) managers' scanning practices influenced their perceptions of key issues. Scanning is the process of collecting internal and external information to interpret environmental stimuli (Watson, 1990). Although IS executives demonstrate consistent scanning behaviors, the quality of communication between CEOs and IS managers affects IS managers' perceptions of the collected information (Watson, 1990). IS managers who have more direct and personal communication with their CEOs have a greater understanding of the strategic goals of the organization, and therefore require less effort on IS planning (Watson, 1990). IS managers without that level of communication require greater planning effort to overcome their lack of strategic understanding (Watson, 1990). Watson (1990) highlights the influence senior management has on the organization in general, and IS specifically. 
Senior management commitment is improving in certain sectors, particularly in organizations supporting critical infrastructure and those that share information with business partners (Holgate \& Hardy, 2012; Patnayakuni \& Patnayakuni, 2014). External pressures are the key drivers behind senior management commitment in critical infrastructure sectors, such as energy, water, health and financial (Holgate \& Hardy, 2012). However, on a broader scope, ISS management continues to be driven from the bottom-up, rather than the top-down (Ahmad, Maynard, \& Park, 2012). ISS strategic development remains a significant gap across many organizations, and one that requires senior management involvement to address (Ahmad et al., 2012; Seeholzer, 2012).

\subsection{ISS Management}

ISS is a management issue, not a technical issue (Dutta \& McCrohan, 2002; Information security governance: Guidance for boards of directors and executive management, 2nd ed, 2006). Dutta and McCrohan (2002) argue that technology is a single component of ISS, but must be balanced with two additional components, organization and critical infrastructures, to achieve security. Organization includes structure; the business environment; culture; policies and procedures; and education, awareness, and training (Dutta \& McCrohan, 2002). Da Veiga and Eloff (2007) proposed an information security governance framework composed of strategic, operational, and tactical levels. Leadership and governance serve the strategic level (Da Veiga \& Eloff, 2007). The operational level includes security management, organization, policies, and user security management (Da Veiga \& Eloff, 2007). The tactical level provides technology protection and operation (Da Veiga \& Eloff, 2007). However, the security 
governance framework did not address some non-technical elements, such as personnel security (Farn, Lin, \& Fung, 2004).

Kankanhalli et al. (2003) argued deterrent efforts, preventive efforts, and punishment severity were ISS management activities that determined ISS effectiveness. Deterrent and preventive efforts were found to increase ISS effectiveness, while no measurable benefit was found from punishment severity (Kankanhalli et al., 2003). This perspective suggests an adversarial relationship between the organization and employees. Other researchers recommend partnership relations. For example, employee participation in ISS risk management, control implementation, and accountability contributes to more effective ISS (Spears \& Barki, 2010). Organizations can improve ISS management by including employees in the design, implementation, testing and monitoring of security controls (Spears \& Barki, 2010).

Effective ISS management is not a standalone activity, but should be founded on a well-developed security strategy (Seeholzer, 2012). ISS security strategies should be balanced with and support business strategies (Chang \& Yeh, 2006; McFadzean, Ezingeard, \& Birchall, 2011). Organizations must be able to assess the effectiveness of ISS and communicate its value to the organization (McFadzean et al., 2011). ISS effectiveness can be assessed internally or externally (Eloff \& von Solms, 2000; Farn et al., 2004; Fung, Farn, \& Lin, 2003; Kwon \& Johnson, 2013). Security assessments can measure compliance with regulatory requirements, security risk, or the balance between technical and non-technical controls (Da Veiga \& Eloff, 2007; Kwon \& Johnson, 2013). Organizations that achieve a greater balance between technical and non-technical controls achieve greater compliance with regulatory requirements and more effective risk 
management (Goode \& Lacey, 2011; Kwon \& Johnson, 2013). Technical controls are well suited to prevent and detect known threats, but are less effective against new or complex threats (Goode \& Lacey, 2011). Non-technical controls can be used to gather the data necessary to develop technical controls to mitigate risk from new or complex threats, thereby reducing costs (Goode \& Lacey, 2011).

ISS risk management is used to identify and quantify security risk to information systems, and develop cost-effective controls to mitigate risk to acceptable levels (Sun et al., 2006). Risk management is the process of understanding and costing the unexpected variability from an activity, and selecting and implementing controls to mitigate that variability (Paquette, Jaeger, \& Wilson, 2010). ISS risk continues to shift as internal and external environments change. Organizations considering new technologies, such as cloud computing, should evaluate and mitigate the associated risks prior to implementing the technology (Paquette et al., 2010). Continuous monitoring or continuous auditing tools aide organizations in active risk management by providing a clearer picture of governance, risk management, and compliance (Kuhn \& Sutton, 2010). Selecting the most effective controls is a complex task that requires a full understanding of the organization, business processes, and information systems (Chen, Kataria, \& Krishma, 2011; Sun et al., 2006).

\subsection{Employee Compliance with ISS Policy and Controls}

When correctly implemented, common ISS controls reduce risk to information systems (Harrison \& White, 2010). User compliance increases the effectiveness of nonautomated ISS controls (Herath \& Rao, 2009b). ISS research has studied employee and 
user compliance extensively. Employee compliance can be achieved through multiple methods, including deterrence, education and training, developing a culture of security, and fear appeals (D'Arcy, Hovav, \& Galletta, 2009; Herath \& Rao, 2009b; Siponen \& Vance, 2010; Son, 2011). Early research on employee compliance focused on general deterrence theory (Kankanhalli et al., 2003; Straub \& Nance, 1990). However, neutralization techniques diminish the effect that fear of sanctions has on users, and reduces the utility of general deterrence theory in achieving employee compliance with security policy (Siponen \& Vance, 2010). Codes of ethics are another type of formal sanction (Harrington, 1996; Siponen \& Vance, 2010), but were found not to deter employees' intent to abuse computer resources when generically applied to the organization (Harrington, 1996). Codes of ethics showed utility on certain employees. Employees with a high degree of denial of responsibility were influenced by codes of ethics (Harrington, 1996). IS-specific codes of ethics showed similar limitations. ISspecific codes of ethics deterred computer sabotage, but otherwise had little impact on deterring intent to abuse computer resources (Harrington, 1996). Security policies, awareness programs, and computer monitoring increased perceived severity of punishment, resulting in reduced intention to abuse computer resources (D'Arcy et al., 2009). Informal sanctions can be employed in addition to formal sanctions, increasing compliance with ISS policies (Siponen, Pahnila, \& Mahmood, 2007).

Deterrence alone will not result in employee compliance with ISS (Puhakainen, 2006; Siponen \& Vance, 2010). Neutralization techniques allow employees to be temporarily relieved from the fear of punishment, thereby enabling them to violate ISS controls in the face of deterrence alone (Siponen \& Vance, 2010). Senior management can 
increase compliance through oversight and continuous communication of ISS expectations, and by instilling the belief in employees in the mandatoriness of the ISS controls (Boss et al., 2009). Mandatoriness is the degree to which employees believe compliance is compulsory (Boss et al., 2009). Senior management fulfills that commitment through ISS governance (Da Veiga \& Eloff, 2007; Ohki, Harada, Kawaguchi, Shiozaki, \& Kagaya, 2009). Senior management sets the foundation for ISS by providing leadership, establishing an ISS vision, assigning roles and responsibilities, and effectively managing ISS (McFadzean et al., 2006).

Management's IT competence and environmental uncertainty in industries positively influence organizational ISS management (Chang \& Ho, 2006). Business managers with greater IT competence assume stronger ISS management leadership roles and demonstrate greater confidence in ISS management (Chang \& Ho, 2006). Environmental uncertainty increases competition within industries, driving IS innovation and increasing dependence on information systems (Chang \& Ho, 2006; Kearns \& Lederer, 2004). Hsu et al. (2012) found different factors influenced adoption and assimilation of ISS management. Adoption was influenced by environmental uncertainty, perceived competitive advantage, and resource availability (Hsu et al., 2012). Assimilation was influenced by senior management support, IS capability, and cultural acceptance (Hsu et al., 2012).

Although ISS research on employee compliance focuses on employee beliefs, attitudes, and behaviors, an underlying theme across these studies is management's role in shaping the desired beliefs, attitudes, and behaviors. For example, employees are more likely to comply with ISS policies they perceive as fair and of good quality (Bulgurcu, 
Cavusoglu, \& Benbasat, 2010b). Therefore, senior management participation that ensures these qualities improves employee compliance with ISS controls. A top-down driven process can also result in a security strategy that is more fully integrated with overall business strategies, and results in the selection of more effective ISS controls (Ahmad et al., 2012; Kwon \& Johnson, 2014).

\subsection{Security Awareness and Training}

Puhakainen (2006) found a comprehensive approach that included security training, a security campaign, rewards, and punishment more effectively achieved employee compliance with ISS controls. Security training provides employees the knowledge and skills necessary to comply with ISS, increasing their ability to comply with ISS controls and their belief they are capable of complying (Pahnila, Siponen, \& Mahmood, 2007; Puhakainen, 2006). A training program that fosters social norms supportive of ISS can improve employee compliance (Dinev, Goo, Hu, \& Nam, 2008). Employees are more likely to comply with ISS controls when they believe the controls are effective and that they are capable of implementing the controls (Bulgurcu et al., 2010a; Johnston \& Warkentin, 2010). ISS awareness and training improves self-efficacy and compliance (Johnston \& Warkentin, 2010). Puhakainen and Siponen (2010) found ISS training programs that consider prior ISS knowledge were more effective. ISS communications that continue after training improve employee compliance (Puhakainen \& Siponen, 2010).

An employee's intention to comply with ISS controls is influenced by their attitude, normative beliefs, and self-efficacy to comply (Bulgurcu et al., 2010a). 
Management can motivate employees to comply by improving security awareness through education that focuses on employee beliefs about intrinsic benefits, individual and organizational safety, and self-efficacy to use the required security controls (Bulgurcu et al., 2010a). Security training that requires active involvement and motivates the participants improves learning and compliance (Puhakainen \& Siponen, 2010). Additional ISS research supports these findings (Herath \& Rao, 2009b; Ifinedo, 2012; Pahnila et al., 2007; Siponen, Pahnila, \& Mahmood, 2010).

Herath and Rao (2009a) underscore the connection between security awareness and training and employee performance. Employees are more likely to comply with ISS controls when they perceive ISS controls benefit the organization, and therefore training should express the belief senior management has that employee compliance improves security (Herath \& Rao, 2009b). Training and awareness that creates or reinforces social norms supportive of ISS motivates employees to comply with ISS (Herath \& Rao, 2009a). Employees are more likely to comply with ISS policy when they perceive their peers believe compliance is important (Herath \& Rao, 2009a).

ISS training and awareness should not be directed solely at employees or users. Evidence suggests management requires ISS training. The security countermeasures selected and implemented by managers are often out of balance with ISS threats and risk (Yeh \& Chang, 2007). Therefore, ISS awareness and training targeted specifically at senior management has been recommended (Killmeyer, 2006; Vroom \& von Solms, 2002). However, little research has been done on the content and methods necessary for senior management ISS training and awareness. 
The skill and creativity of ISS professionals is another important aspect of security awareness and training. Over dependence on formally structured ISS processes and controls can limit organizational response to ISS risk (Njenga \& Brown, 2012). Njenga and Brown (2012) argue that skilled ISS professionals can add significant value to ISS when they are allowed to improvise and use their creativity, particularly in the areas of governance and regulatory compliance. Strict reliance on rule-based ISS can lead to deskilling ISS professionals and limit their ability to manage new and challenging risk scenarios (Njenga \& Brown, 2012). Proactive ISS investments have a greater positive impact on organizations than reactive investments (Kwon \& Johnson, 2013), further emphasizing the need for skilled and educated ISS professionals. ISS professionals need the awareness of not only the threats and vulnerabilities as seen internally in their organizations, but a global awareness of threats, vulnerabilities, and countermeasures (Kwon \& Johnson, 2013).

Security awareness and training can be the genesis for developing an ISS culture (Corriss, 2010; Drevin, Kruger, \& Steyn, 2007). Value-focused training identifies all that is important to users. Training objectives developed from values can shape an organization's ISS culture (Drevin et al., 2007).

\subsection{Security Culture}

Researches widely agree that both technical and socio-organizational elements must be addressed to ensure effective ISS (Bjorck, 2004; Dhillon \& Backhouse, 2001; Drevin et al., 2007; Siponen \& Willison, 2005). Understanding the role of culture is fundamental to successful ISS (Knapp, Marshall, Rainer, \& Ford, 2006). Culture is the 
product of group learning over a period of time as the group solves problems (Schein, 1990). Culture is defined as:

(a) a pattern of basic assumptions, (b) invented, discovered, or developed by a given group, (c) as it learns to cope with its problems of external adaptation and internal integration, (d) that has worked well enough to be considered valid and, therefore (e) is to be taught to new members as the (f) correct way to perceive, think, and feel in relation to those problems (Schein, 1990, p. 111) .

Information security culture is the perceptions and attitudes accepted and encouraged to incorporate information security as the way things are done in an organization (Martins \& Eloff, 2002). ISS culture a basic pattern of assumptions invented or developed by a group to deal with risk to information systems that has worked well enough to be taught to new members as the correct way to perceive, think, and feel about ISS.

Because ISS culture is learned, management can cultivate the ISS culture within organizations (Da Veiga \& Eloff, 2007). Da Veiga and Eloff (2010) argue that management can systematically plan an organization's security culture, and that the first step is assessment of the existing security culture. Not only can management create an ISS culture, but the responsibility for creating the ISS culture rests on management's shoulders (Baggett, 2003). The Organization of Economic Cooperation and Development (OECD) provides guidelines for discussing and assessing organizational security culture $(O E C D$ guidelines for the security of information systems and networks: Towards a culture of security, 2002). The guidelines provide nine principles for creating an ISS culture: 
awareness, responsibility, response, ethics, democracy, risk assessment, security design and implementation, and reassessment (OECD guidelines for the security of information systems and networks: Towards a culture of security, 2002). Senior management is responsible for four fundamental duties to implement these principles: stating the policy, directing action plans, reviewing results, and taking corrective actions (Baggett, 2003). These responsibilities are reflected in the ISS governance framework proposed by McFadzean et al. (2006). Senior management shapes IS and ISS culture by assessing information systems and safeguarding the interests of stakeholders (McFadzean et al., 2006). The principle of good management practice mandates that senior management will develop, monitor, and review IS control structures and will manage ISS risk (McFadzean et al., 2006).

Knapp et al. (2006) reinforces the critical linkage between socio-organizational factors and ISS success. Senior management support for ISS positively influences ISS culture and employee compliance with ISS policy (Knapp et al., 2006). ISS researchers have called for a deeper examination of senior management support for ISS (Da Veiga \& Eloff, 2010; Johnson, 2009; Knapp et al., 2006).

\subsection{Senior Management Commitment to ISS}

There is consensus among ISS researchers that senior management commitment is necessary for effective ISS (Boss et al., 2009; Herath \& Rao, 2009a; Holgate \& Hardy, 2012; Knapp et al., 2006; Patnayakuni \& Patnayakuni, 2014), but ISS research related to senior management commitment is limited (Johnson, 2009). Exploratory research has identified key drivers that motivate senior management commitment to ISS (Johnson, 
2009). These drivers can be categorized as primarily internal or external. External drivers dominated the factors that motivate senior management to invest in ISS (Johnson, 2009). Empirical evidence demonstrates external mimetic, coercive, and normative influences can sway senior management to purchase ISS technology (Lee \& Larsen, 2009). Key external drivers included compliance with and ability to demonstrate compliance with regulations; protecting customer data integrity and confidentiality; pressures from business partners; and ability to compete with other companies (Johnson, 2009). However, senior management commitment was not evaluated (Johnson, 2009). Although senior managers identified factors that would drive their investment in ISS, the study did not assess senior management commitment to ISS (Johnson, 2009). Lee and Larsen (2009) found external pressures impacted senior management commitment to security controls by altering their threat and coping appraisals.

Holgate and Hardy (2012) consistently found executive or board-level commitment to ISS in critical infrastructure organizations. In most cases, CEOs or CIOs had primary responsibility for ISS governance (Holgate \& Hardy, 2012). Key drivers to senior management commitment were from regulatory pressures, normative pressures through professional organizations, and imitation of perceived best practices (Holgate \& Hardy, 2012). However, the full integration of ISS governance with corporate or IT governance remains limited in most organizations (Holgate \& Hardy, 2012), even though researchers argue that ISS should be fully integrated into organizational planning and strategy (McFadzean et al., 2006, 2011; Patnayakuni \& Patnayakuni, 2014)

Research shows effective ISS reduces organizational risk, and senior management commitment is critical to effective ISS. Senior management commitment is demonstrated 
by committing resources to ISS (Johnson, 2009; Lee \& Larsen, 2009), assigning roles and responsibilities for ISS (Dhillon, Tejay, \& Hong, 2007; McFadzean et al., 2006;

Patnayakuni \& Patnayakuni, 2014), communicating the ISS vision (Cho, Park, \& Michel, 2011; McFadzean et al., 2006; Patnayakuni \& Patnayakuni, 2014; Seeholzer, 2012; von Solms \& von Solms, 2006a) and monitoring compliance (Herath \& Rao, 2009a; McFadzean et al., 2006). However, research also shows senior managers often lack commitment to ISS (Chang \& Ho, 2006; Hsu, 2009; Hu et al., 2007; Smith et al., 2010). Understanding how to motivate senior management commitment is important to improving ISS in organizations.

IS and ISS research show not only is senior management a dominant driver for organizational behavior (Enns et al., 2003; Hu et al., 2007), but senior managers are also the key human agents between organizations and the external environment (Liang et al., 2007). Further, senior managers are motivated by different factors than employees regarding ISS (Johnson, 2009). Therefore, understanding how external influences motivate senior management commitment to ISS is important to improving ISS within organizations.

\subsection{Summary}

ISS training and awareness helps create an ISS culture within organizations, and a strong culture improves the effectiveness of ISS controls (Knapp et al., 2006; Pahnila et al., 2007; Puhakainen \& Siponen, 2010). ISS controls reduce ISS risk (Harrison \& White, 2010). However, senior management commitment is needed to gain the greatest benefit from ISS training and awareness, to develop an ISS culture, and to effectively manage ISS 
controls (Boss et al., 2009; Bulgurcu et al., 2010a; Chai et al., 2011; Da Veiga \& Eloff, 2007; Hu et al., 2007; Kankanhalli et al., 2003; McFadzean et al., 2006). Considering the fundamental value of senior management commitment to effective ISS, it is important to understand the factors that motivate senior management commitment to ISS (Johnson, 2009). Pressures external to organizations have greater influence on senior management than internal personnel or pressures (Dutton et al., 2001; Dutton \& Ashford, 1993; Holgate \& Hardy, 2012; Liang et al., 2007; Smith et al., 2010). Therefore, understanding how external influences motivate senior management participation in ISS is key to improving ISS in organizations. 


\section{Chapter 3}

\section{Research Methodology}

\subsection{Introduction}

Chapter 3 is organized in five sections. Section 3.2 describes the researcher's epistemology and research method selection. Section 3.3 describes the research model. Section 3.4 describes research design. Section 3.5 explains limitations and delimitations. Section 3.6 summarizes the chapter.

\subsection{Epistemology and Research Method}

The researcher holds an objectivist view. Specific to this research, the researcher believes senior management's beliefs about ISS and their participation in ISS are outcomes, or effects, in response to a set of causes. Understanding the relationships between those causes and effects could enable researchers and practitioners to steer senior management to the desired behavior by controlling the causes that shape the behavior. A better understanding of the influences that motivate senior management participation in ISS could enable practitioners to create greater pressure through those influences, thereby shaping their belief and participation in ISS. This deterministic philosophy is held by postpositivists (Creswell, 2009).

Researchers with a postpositivism epistemology attempt to extend knowledge through theory development and verification using observation and measurement (Creswell, 2009). Quantitative research remains the foundation of postpositivism 
(Creswell, 2009). This research attempts to explain how external influences motivate senior management commitment to ISS by examining the mediating role of senior management between external influences and ISS assimilation. The goal of this research is to develop a better theoretical understanding of the relationship between external influences and senior management commitment to ISS, and is grounded in postpositivism. Therefore, quantitative research is appropriate.

\subsection{Research Model}

This study adopted neo-institutional theory to examine how external influences motivate senior managers to participate in ISS by examining coercive, mimetic and normative mechanisms (DiMaggio \& Powell, 1983; Hu et al., 2007; Liang et al., 2007). Figure 3.1 illustrates neo-institutional theory as developed by DiMaggio and Powell (1983). Coercive, mimetic, and normative processes are hypothesized to positively influence organizational homogeneity through the process of isomorphism (DiMaggio \& Powell, 1983). Neo-institutional theory proposed six hypotheses. $\mathrm{H} 1$ and $\mathrm{H} 2$ are coercive processes, $\mathrm{H} 3$ and $\mathrm{H} 4$ are mimetic processes, and $\mathrm{H} 5$ and $\mathrm{H} 6$ are normative processes (DiMaggio \& Powell, 1983). Liang et al. (2007) modified DiMaggio and Powell's theoretical model by holding coercive, mimetic, and normative processes as the exogenous constructs. Liang et al. used the factors posited as hypotheses by DiMaggio and Powell, and additional factors, to operationalize the constructs of coercive, mimetic, and normative processes.

Figure 3.2 illustrates the theoretical framework for this research. Coercive, mimetic, and normative mechanisms are independent constructs (Hu et al., 2007; Liang et 
al., 2007; Teo, Wei, \& Benbasat, 2003). Senior management commitment, composed of senior management belief in ISS and senior management participation in ISS, was added as a mediating construct (Liang et al., 2007). Liang et al. provided a deeper examination of

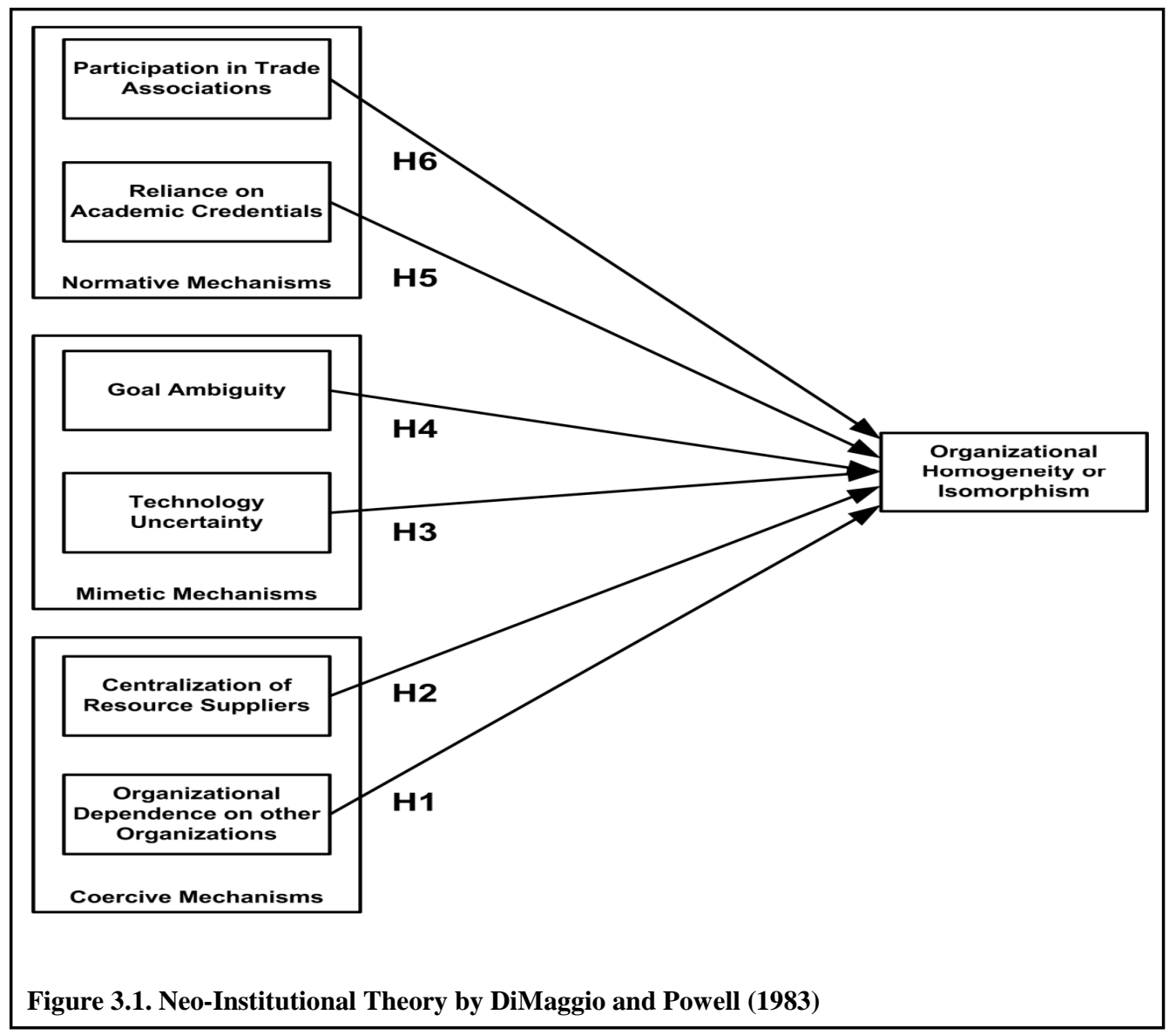

senior management commitment by dividing commitment into two parts: senior management belief and senior management participation, as illustrated in Figure 3.2. This study extended the two components of senior management commitment, belief and participation, from IS to ISS research.

Senior management belief in ISS and senior management participation in ISS are mediating constructs between external influences and ISS assimilation (Liang et al., 2007; 
McFadzean et al., 2006; Teo et al., 2003). Senior management belief in ISS also influences senior management participation in ISS (Liang et al., 2007). Mimetic mechanisms influence senior management belief, and directly influence senior management participation (Liang et al., 2007). Normative mechanisms directly influence senior management belief (DiMaggio \& Powell, 1983; Liang et al., 2007). Senior management participation in ISS is evidenced by their actions to establish authority and responsibilities, communicate a vision, manage, lead, and align ISS with organizational strategy (McFadzean et al., 2006, 2011). The dependent construct is ISS assimilation (Liang et al., 2007; Teo et al., 2003).

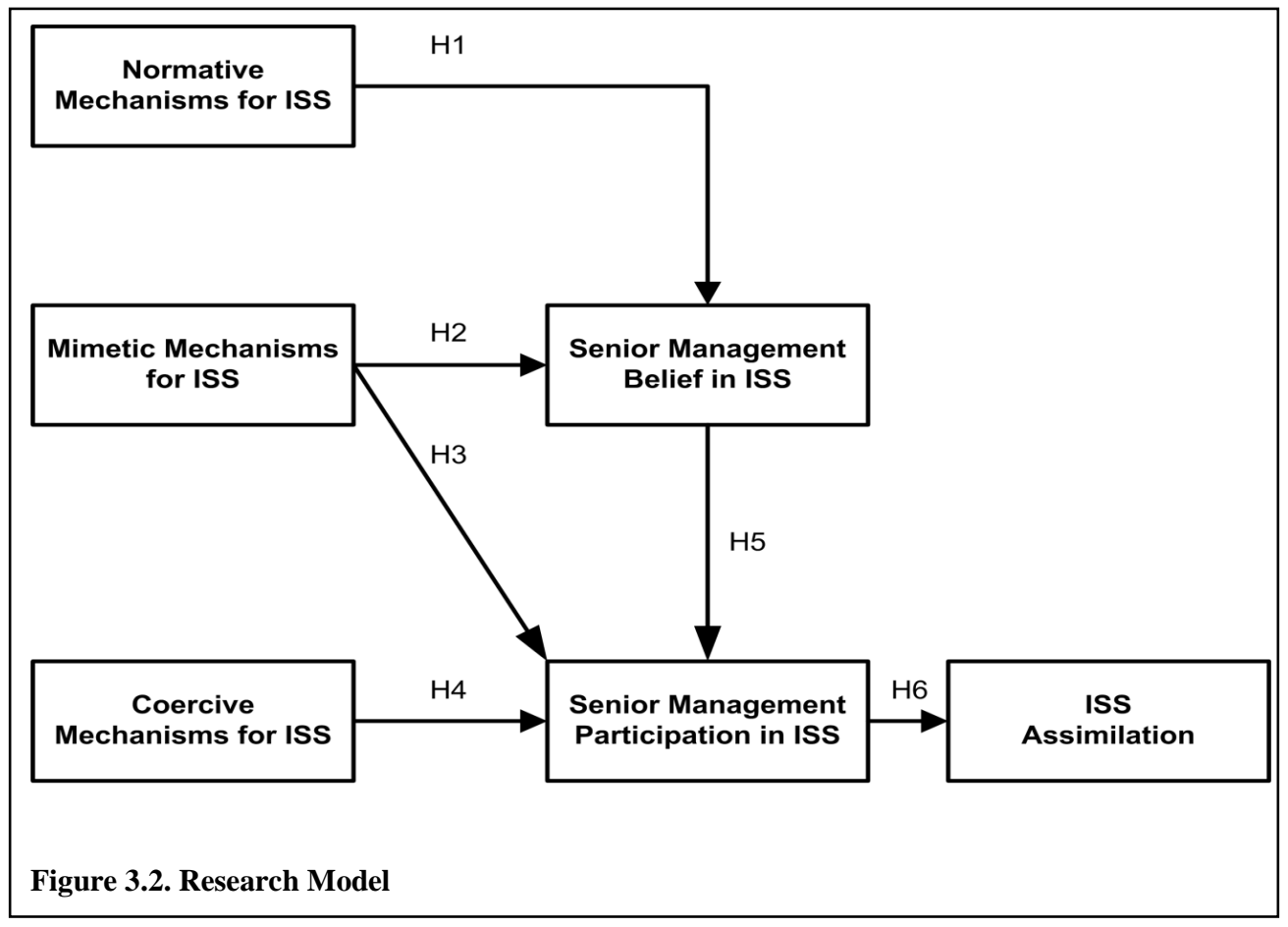

The theoretical model for this study was developed from DiMaggio and Powell (1983), Liang et al. (2007), and Hu et al. (2007). Liang et al. hypothesized normative mechanisms would directly influence senior management participation. However, this 
study hypothesized normative mechanisms also influence senior management beliefs, which in turn influence senior management participation in ISS. Liang et al. theorized normative mechanisms directly influence senior management participation, but found normative mechanisms did not directly influence senior management participation. Instead, Liang et al. found normative mechanisms directly influence organizational change without influencing senior management participation. This finding could have been a deficiency with the scale. Liang et al. used the following items to measure normative mechanisms:

1. "The extent of ERP adoption by your firm's suppliers"

2. "The extent of ERP adoption by your firm's customers"

3. "The extent to which the Government's promotion of Information Technology influences your firm to use ERP”

Normative mechanisms have two important sources: formal education and professional networks (DiMaggio \& Powell, 1983). Teo et al. (2003) evaluated normative mechanisms by adoption of a technology by suppliers and customers, but the focus was on shared learning as a result of adopting the technology. The instrument used by Liang et al. (2007) could have measured supplier, customer, and government pressures to adopt ERP for normative mechanisms, rather than shared learning from adoption of ERP by partners. Normative mechanisms are manifested through common education and training with the intent to establish a "cognitive base" (DiMaggio \& Powell, 1983, p. 152), and as a result should influence beliefs. Liang et al. theorized normative mechanisms would directly 
influence participation, rather than beliefs. ISS research shows information security training influences beliefs (Hu et al., 2007; Johnston \& Warkentin, 2010). Therefore, this study theorized ISS education and training influence senior management beliefs.

Hypothesis 1: Normative mechanisms related to ISS positively influence senior management belief in the need for ISS.

Mimetic mechanisms are important in uncertain environments or when technologies are not understood (DiMaggio \& Powell, 1983). In such situations, organizations tend to mimic organizations they perceive as successful (DiMaggio \& Powell, 1983). Mimetic mechanisms can either change beliefs or directly influence action without affecting beliefs (Liang et al., 2007). Liang et al. found mimetic mechanisms influenced senior management beliefs. This study extended the conceptual framework for mimetic mechanisms from IS research to ISS research, and theorized mimetic mechanisms (a) influence senior management beliefs in ISS, and (b) directly influence senior management participation in ISS.

Hypothesis 2: Mimetic mechanisms related to ISS positively influence senior management belief in ISS.

Hypothesis 3: Mimetic mechanisms related to ISS positively influence senior management participation in ISS. 
Coercive mechanisms result from formal or informal pressures to adopt practices or structures that an organization considers necessary to be viewed as legitimate in the culture or environment where they operate (DiMaggio \& Powell, 1983). Coercive forces influence senior management commitment (Teo et al., 2003) and directly influence senior management participation during IS assimilation (Liang et al., 2007). Hu et al. (2007) provided anecdotal evidence that coercive mechanisms influenced senior management commitment to ISS. This study theorized coercive mechanisms directly influence senior management participation in ISS.

Hypothesis 4: Coercive mechanisms related to ISS positively influence senior management participation in ISS.

Liang et al. (2007) found senior management belief was a mediating variable between isomorphic forces and senior management participation during IS assimilation, and showed senior management participation was positively influenced by senior management beliefs. User beliefs about ISS threats, their susceptibility to those threats, effectiveness of responses, and their ability to implement the responses positively influence intent to comply with ISS policy (Johnston \& Warkentin, 2010; Puhakainen \& Siponen, 2010). This study held that ISS is a response by senior management to ISS threats to the organization, and therefore theorized greater levels of belief in the need for ISS to protect against threats influence greater commitment to ISS by senior management. 
Hypothesis 5: Senior management belief in the need for ISS positively influences senior management participation in ISS.

Senior management determines which issues become an organization's strategic issues, and as a result which issues get the resources and organizational commitment needed to implement initiatives and programs (Dutton et al., 2001; Dutton \& Ashford, 1993). ISS adoption and employee compliance with ISS are related to senior management commitment to ISS (Herath \& Rao, 2009b; Hsu, 2009; Hu et al., 2007; Puhakainen \& Siponen, 2010; Smith et al., 2010; von Solms \& von Solms, 2006b). This study theorized senior management commitment to ISS directly influences ISS assimilation (Liang et al., 2007; McFadzean et al., 2006).

Hypothesis 6: Senior management participation in ISS positively influences ISS assimilation.

\subsection{Research Design}

The research method for this study was survey research. Survey research is appropriate for correlational studies in IS research (Bjorck, 2004; Mishra \& Agarwal, 2009; Sekaran \& Bougie, 2010; Siponen \& Willison, 2005; Straub, 1989; Teo et al., 2003; Xue, Liang, \& Wu, 2010). Survey research is useful to determine relationships among constructs to understand the behavior surrounding and involving IS (Pinsonneault \& Kraemer, 1993; Salkind, 2009; Sekaran \& Bougie, 2010). Surveys can produce quantitative descriptions of trends, attitudes, or opinions within a specific population and 
may include the study of relationships among variables (Creswell, 2009; Pinsonneault \& Kraemer, 1993). Survey data is usually obtained from a sample of the population in an approach supporting generalization to the greater population (Pinsonneault \& Kraemer, 1993).

This dissertation tested hypotheses to determine if relationships exist between constructs and the directionality between those constructs. The results contribute to the development of a theory explaining how senior management mediates the relationship between external influences on organizations and the assimilation of ISS within organizations. Explanatory survey research is recommended for theory building, particularly when attempting to explain directionality between variables or constructs (Pinsonneault \& Kraemer, 1993). Correctly implemented surveys provide insight into participants' perceptions and organizational practices (Karanja, 2013). This dissertation considered the relationship between senior management beliefs about ISS and senior management participation in ISS within the organization. The study also examined the extent to which ISS is assimilated in organizations by examining organizational practices. Survey research was an appropriate choice for meeting those objectives (Karanja, 2013). Similar IS and ISS studies have also used explanatory survey research (Enns et al., 2003; Liang et al., 2007; Teo et al., 2003).

Certain data collection methods in survey research are also credited as efficient and cost effective (Pinsonneault \& Kraemer, 1993). Internet-based questionnaires have been credited with the ability to collect data from a broad geographic region and from multiple cultures in a short period of time (Fox, Murray, \& Warm, 2003). This study collected data from multiple industries and organizations throughout south-central United 
States. Therefore, Internet-based questionnaire provides a good method for data collection (Fox et al., 2003).

This survey research used matched pair questionnaire surveys to reduce the effects of common method bias. Enns et al. (2003) utilized matched pair surveys to reduce the risk of common method bias. Separate surveys were used to measure dependent and independent variables, thereby reducing the risk of variances caused by the measurement (Enns et al., 2003). This study employed a similar technique.

\subsubsection{Data Collection}

Convenience sampling is appropriate for exploratory research (Sekaran \& Bougie, 2010), and was selected as the sampling method for this study. The study population was small- and medium-sized enterprises (SMEs) throughout south-central United States. SMEs face unique challenges compared to large organizations which impact their ability to develop and implement ISS (Lee \& Larsen, 2009; Sánchez, Parra, Rosado, \& Piattini, 2009; Thong, 1999). SMEs are often faced with greater resource constraints and lack ISS expertise, training, and education (Thong, 1999). Prior IS and ISS research has found regulatory requirements, customer expectations, supplier expectations, and ISS assimilation varies by industry (Chang \& Ho, 2006; Kearns \& Lederer, 2004). Therefore, examining multiple industries provided a better understanding of the relationships between external influences, senior management beliefs and participation in ISS, and ISS assimilation within organizations. Senior management commitment is critical to overcoming these obstacles. This study focused on external influences impacting SMEs in a cross-section of industries. 
Data collection was through online survey. Online surveys are recommended when the sample size is large, the participants are widely dispersed, a fast turn-around is preferred, the participants have Internet access, and anonymity is needed (Sue \& Ritter, 2012). This dissertation met that criteria, and therefore online survey was appropriate.

This research extended earlier IS and ISS research using surveys (Hu et al., 2007; Liang et al., 2007; Teo et al., 2003), but was adapted as an online survey. Prior IS research with a mail survey targeted to CEOs, CFOs, and CIOs demonstrated the utility of mail surveys with senior management (Teo et al., 2003). Mail surveys targeting senior management have been effectively employed in additional IS research (Enns et al., 2003; Johnson \& Lederer, 2010). The delivery format was modified from mail survey to online survey. Researchers have cautioned against the use of mail surveys in survey and ISS research, noting the lack of trust between organizations and researchers as a key impediment (Kotulic \& Clark, 2004). Specifically, organizations are concerned about revealing sensitive security information or vulnerabilities to researchers (Kotulic \& Clark, 2004). However, this study only collected data on senior management's exposure to external influences and their response to participate in ISS. ISS assimilation was measured, not ISS effectiveness or gaps. Therefore, online survey was appropriate for this study.

Determining the sample size for studies employing PLS-SEM is widely debated (Gefen \& Rigdon, 2011; Goodhue, Lewis, \& Thompson, 2006; Marcoulides \& Saunders, 2006; Ringle, Sarstedt, \& Straub, 2012). Some researchers propose a rule of thumb standard that is 10 times the number of measurement items for the most complex construct (Chin, 1998b; Gefen, Straub, \& Bourdreau, 2000; Hair, Ringle, \& Sarstedt, 2011). Other 
researchers argue power analysis should be used to determine the sample size (Chin, 2010; Cohen, 1988; Ringle et al., 2012). The most complex construct in the research model has 7 items, suggesting a minimum of 70 responses are needed (Gefen et al., 2000; Hair et al., 2011). However, Cohen (1992) noted the relationship between power and sample size. Sample size increases as desired power increases (Cohen, 1992). Power analysis considers the effect among sample size, significance criterion, population effect size, and statistical power (Cohen, 1988, 1992). Goodhue et al. (2006) examined the reliability of various sample sizes and effect sizes. The commonly accepted rule of 10 times the most complex relationship in the model was only reliable when there was a strong effect size (Goodhue et al., 2006). For the same model, a sample size of 90 was needed to accurately detect medium effect sizes (Goodhue et al., 2006). A much larger sample size is required to detect small effect sizes (Cohen, 1992; Goodhue et al., 2006; Westland, 2010). Large effect size is .35 , medium effect size is .15 , and small effect size is .02 for studies using multiple linear regression (Cohen, 1988, 1992; Goodhue et al., 2006).

Sample size was estimated using several methods. Sample size was first estimated using $\mathrm{G}^{*}$ Power 3.1.7's linear multiple regression fixed model, single regression coefficient test (Erdfelder, Faul, \& Buchner, 1996; Faul, Erdfelder, Lang, \& Buchner, 2007). Input parameters were effect size $f^{2}=.15$, significance level $\alpha=.05$, and power ( 1 $-\beta)=.80$. Estimated sample size was 45 . However, the estimated sample size should consider the control variables. This study has two control variables. Kraemer and Thiemann (1987) state each control variable must be considered a cell, and the calculated sample size is needed for each cell. Therefore, a sample size of 90 is required. These results were compared to Goodhue et al. (2006) for the sample size needed to measure 
medium effect $(1-\beta)=.80$ and $\alpha=.05$. Goodhue et al. (2006) found a larger sample size was needed to reliably detect medium effect size. Sample size estimates by Kraemer and Thiemann (1987) were also considered. Kraemer and Thiemann (1987) recommend a sample size of 272 for the power, significance level, and effect size of this study.

However, a sample size of 150 is sufficient to detect an effect size of $f^{2}=.20$ given this study's power and significance level (Kraemer \& Thiemann, 1987). A sample size of 150 was used for this study. A sample size of 150 reliably detects strong, medium, and no effect sizes, but does not have sufficient power to detect weak effect sizes (Faul et al., 2007; Goodhue et al., 2006). This is appropriate for exploratory research (Hair et al., 2011). Therefore, this study employed a sample size of 150 , recognizing the limitation to detect weak effect sizes.

\subsubsection{Instrument Development}

Figure 3.3 illustrates the constructs for this research. The research model consists

of three exogenous and three endogenous constructs. Absorptive capacity is introduced as a control variable (Liang et al., 2007). Absorptive capacity is the readiness of an organization to implement a technology (Clark, Jones, \& Armstrong, 2007; Cohen \& Levinthal, 1990; Kouki, Poulin, \& Pellerin, 2010; Liang et al., 2007; Roberts, Galluch, Dinger, \& Grover, 2012). Prior knowledge of a technology within an organization is one factor of absorptive capacity (Cohen \& Levinthal, 1990; Liang et al., 2007). ISS research shows a second factor is financial resource constraints (Gupta \& Hammond, 2005; Karyda, Mitrou, \& Quirchmayr, 2006; Wang, Xu, Lu, \& Shen, 2009). For this study, absorptive capacity is defined as the readiness of an organization to adopt ISS based on prior knowledge of ISS and sufficient resources. Organizations with greater absorptive 
capacity can better assimilate ISS, and organizations with limited absorptive capacity will be less capable of assimilating ISS even if senior management is committed (Cohen \& Levinthal, 1990; Liang et al., 2007).

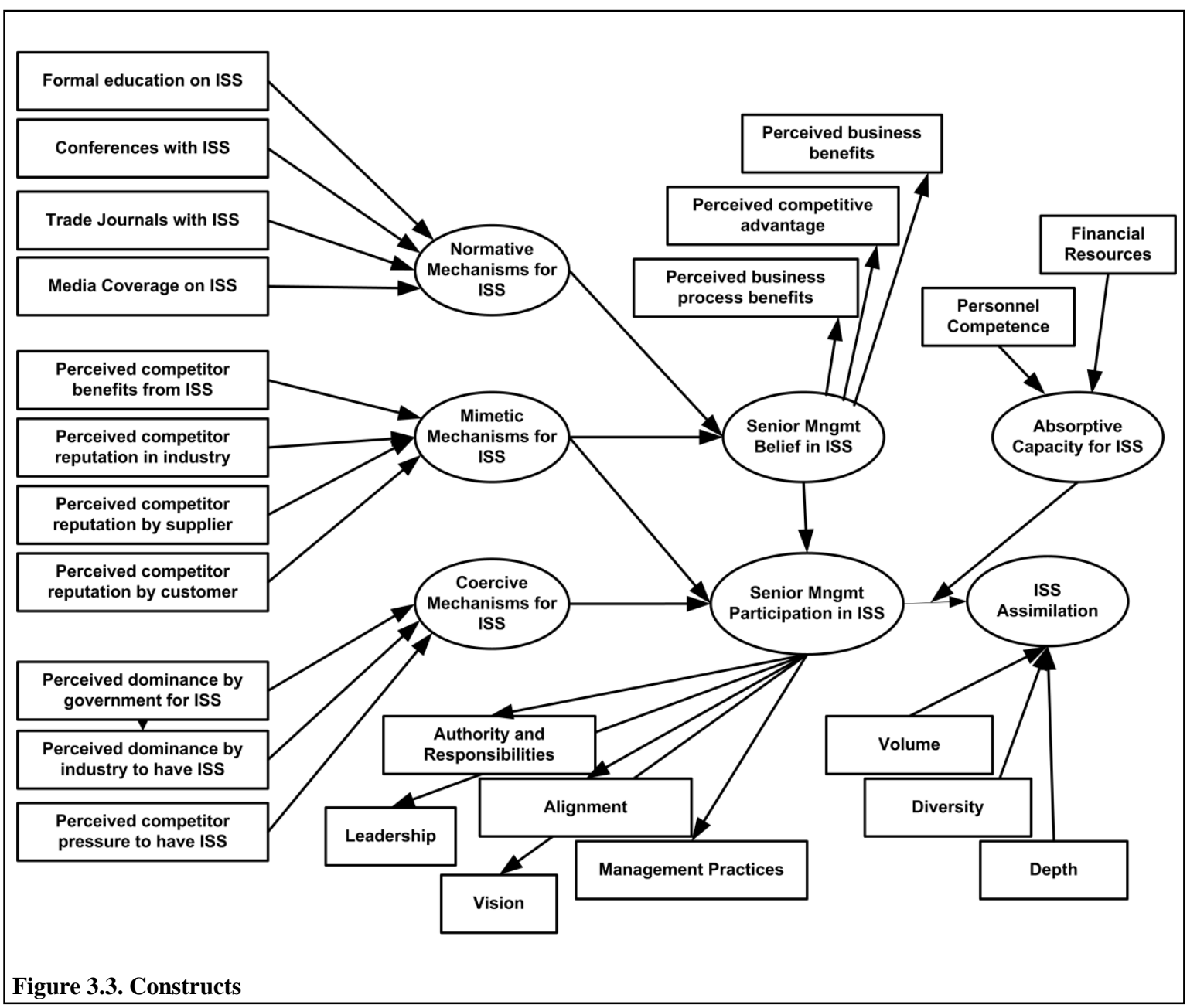

Table 3.1 supports the measurement items for the exogenous constructs from ISS literature and Table 3.2 supports the measurement items for the endogenous constructs from ISS literature. The exogenous constructs developed by Teo et al. (2003) were properly specified as formative constructs (Petter, Straub, \& Rai, 2007). Petter et al. did not comment on the constructs from Chatterjee et al. (2002), and did not evaluate the 
constructs from Liang et al. (2007). The constructs developed by Chatterjee et al. and Liang et al. were evaluated using criteria by Petter et al., and with one exception, found to be properly specified. Liang et al. specified the four-item construct to measure absorptive capacity as reflective. Causality in reflective constructs extends from the construct to the measure, where causality is from the measure to the construct in formative constructs (MacCallum \& Browne, 1993; Petter et al., 2007). Causality in the absorptive capacity construct is from the measure to the construct (Liang et al., 2007). Organizations with limited financial resources or lacking ISS expertise are less capable of implementing ISS. Therefore, the construct should have been specified as formative rather than reflective. Liang et al.'s scale for absorptive capacity was modified for this study and specified as a formative construct.

This study adapted the exogenous constructs of normative, mimetic, and coercive mechanisms from Liang et al. (2007). Senior management commitment was divided into two constructs, senior management belief and senior management participation (Chatterjee et al., 2002; Liang et al., 2007). Scales for senior management belief and senior management participation were adapted from IS research (Chatterjee et al., 2002; Liang et al., 2007). A three item reflective scale measured senior management beliefs (Liang et al., 2007). A seven-item reflective scale was adapted to measure senior management participation based on the principles of ISS governance (Liang et al., 2007; McFadzean et al., 2006). A five-item formative scale was adapted to measure ISS assimilation (Liang et al., 2007; Massetti \& Zmud, 1996). The scale measured three facets of ISS assimilation: volume, diversity, and depth (Liang et al., 2007; Massetti \& Zmud, 1996). Volume is the extent to which an organization adopts information system 
security in their business processes (Liang et al., 2007; Massetti \& Zmud, 1996).

Diversity is the extent to which ISS is adopted by the different functions in an organization (Liang et al., 2007; Massetti \& Zmud, 1996). Depth is the extent to

Table 3.1

Definitions, Measurement Items, and Supporting Literature for Exogenous Constructs

\begin{tabular}{|c|c|c|c|}
\hline Construct & Definition & Item & Supporting Literature \\
\hline \multirow{3}{*}{$\begin{array}{l}\text { Normative } \\
\text { mechanisms for } \\
\text { ISS }\end{array}$} & \multirow{3}{*}{$\begin{array}{l}\text { Professionalization of } \\
\text { senior managers in ISS } \\
\text { through common } \\
\text { education and training } \\
\text { that results in similar ISS } \\
\text { skills and knowledge }\end{array}$} & $\begin{array}{l}\text { Formal education on } \\
\text { ISS }\end{array}$ & $\begin{array}{l}\text { Hsu (2009) } \\
\text { Hu et al. (2007) }\end{array}$ \\
\hline & & $\begin{array}{l}\text { Conferences with } \\
\text { ISS }\end{array}$ & $\begin{array}{l}\text { Hsu (2009) } \\
\text { Hu et al. (2003) }\end{array}$ \\
\hline & & $\begin{array}{l}\text { Trade journals with } \\
\text { ISS }\end{array}$ & $\begin{array}{l}\text { Hsu (2009) } \\
\text { Hu et al. (2003) }\end{array}$ \\
\hline \multirow[t]{4}{*}{$\begin{array}{l}\text { Mimetic } \\
\text { mechanisms for } \\
\text { ISS }\end{array}$} & \multirow{4}{*}{$\begin{array}{l}\text { Influences that cause } \\
\text { organizations to copy ISS } \\
\text { practices they attribute to } \\
\text { the success of other } \\
\text { organizations }\end{array}$} & $\begin{array}{l}\text { Perceived } \\
\text { competitor benefits } \\
\text { from ISS }\end{array}$ & $\begin{array}{l}\text { Hsu (2009) } \\
\text { Johnson (2009) }\end{array}$ \\
\hline & & $\begin{array}{l}\text { Perceived } \\
\text { competitor } \\
\text { reputation in } \\
\text { industry }\end{array}$ & Hsu (2009) \\
\hline & & $\begin{array}{l}\text { Perceived } \\
\text { competitor } \\
\text { reputation by } \\
\text { supplier }\end{array}$ & Hsu (2009) \\
\hline & & $\begin{array}{l}\text { Perceived } \\
\text { competitor } \\
\text { reputation by } \\
\text { customer }\end{array}$ & $\begin{array}{l}\text { Hsu (2009) } \\
\text { Johnson (2009) }\end{array}$ \\
\hline \multirow[t]{3}{*}{$\begin{array}{l}\text { Coercive } \\
\text { mechanisms for } \\
\text { ISS }\end{array}$} & \multirow{3}{*}{$\begin{array}{l}\text { External influences from } \\
\text { regulatory sources, } \\
\text { competition, and society } \\
\text { that pressure } \\
\text { organizations to } \\
\text { implement ISS }\end{array}$} & $\begin{array}{l}\text { Perceived } \\
\text { dominance by } \\
\text { government for ISS }\end{array}$ & $\begin{array}{l}\text { Johnson (2009) } \\
\text { Hsu (2009) } \\
\text { Hu et al. (2007) }\end{array}$ \\
\hline & & $\begin{array}{l}\text { Perceived } \\
\text { dominance by } \\
\text { industry to have ISS }\end{array}$ & $\begin{array}{l}\text { Johnson (2009) } \\
\text { Hsu (2009) }\end{array}$ \\
\hline & & $\begin{array}{l}\text { Perceived } \\
\text { competitor pressure } \\
\text { to have ISS }\end{array}$ & $\begin{array}{l}\text { Johnson (2009) } \\
\text { Hsu (2009) }\end{array}$ \\
\hline
\end{tabular}


Table 3.2

Definitions, Measurement Items, and Supporting Literature for Endogenous Constructs

\begin{tabular}{|c|c|c|c|}
\hline Construct & Definition & Item & Supporting Literature \\
\hline \multirow{3}{*}{$\begin{array}{l}\text { Senior } \\
\text { management belief } \\
\text { in ISS }\end{array}$} & \multirow{3}{*}{$\begin{array}{l}\text { The extent to which senior } \\
\text { management believes ISS } \\
\text { can benefit the } \\
\text { organization }\end{array}$} & $\begin{array}{l}\text { Perceived benefits of } \\
\text { ISS }\end{array}$ & Lee and Larsen (2009) \\
\hline & & $\begin{array}{l}\text { Perceived competitive } \\
\text { advantage of ISS }\end{array}$ & Johnson (2009) \\
\hline & & $\begin{array}{l}\text { Perceived advantage to } \\
\text { business processes from } \\
\text { ISS }\end{array}$ & Johnson (2009) \\
\hline \multirow{5}{*}{$\begin{array}{l}\text { Senior } \\
\text { management } \\
\text { participation in } \\
\text { ISS }\end{array}$} & \multirow{5}{*}{$\begin{array}{l}\text { The extent to which senior } \\
\text { management actively } \\
\text { participates in ISS } \\
\text { management }\end{array}$} & $\begin{array}{l}\text { Assigning authority and } \\
\text { responsibility for ISS }\end{array}$ & $\begin{array}{l}\text { Dhillon et al. (2007) } \\
\text { McFadzean et al. (2011) }\end{array}$ \\
\hline & & $\begin{array}{l}\text { Alignment of ISS with } \\
\text { strategic objectives }\end{array}$ & McFadzean et al. (2011) \\
\hline & & $\begin{array}{l}\text { Good ISS management } \\
\text { practices }\end{array}$ & $\begin{array}{l}\text { McFadzean et al. (2011) } \\
\text { Pahnila (2007) }\end{array}$ \\
\hline & & Leadership in ISS & $\begin{array}{l}\text { McFadzean et al. (2011) } \\
\text { Pahnila (2007) }\end{array}$ \\
\hline & & $\begin{array}{l}\text { Communicating a } \\
\text { vision for ISS }\end{array}$ & $\begin{array}{l}\text { Cho et al. (2011) } \\
\text { McFadzean et al. (2011) } \\
\text { Seeholzer (2012) } \\
\text { von Solms and von Solms } \\
(2006 \text { a) }\end{array}$ \\
\hline \multirow[t]{3}{*}{ ISS assimilation } & \multirow{5}{*}{$\begin{array}{l}\text { The extent to which ISS is } \\
\text { diffused across an } \\
\text { organization's work } \\
\text { processes, and becomes } \\
\text { routine in those processes }\end{array}$} & $\begin{array}{l}\text { Volume of ISS } \\
\text { coverage in } \\
\text { organization }\end{array}$ & Doherty and Fulford (2006) \\
\hline & & $\begin{array}{l}\text { Diversity of ISS in } \\
\text { organization }\end{array}$ & $\begin{array}{l}\text { Cavusoglu, Mishra, and } \\
\text { Raghunathan (2004) } \\
\text { Cavusoglu, Raghunathan, } \\
\text { and Cavusoglu (2009) }\end{array}$ \\
\hline & & $\begin{array}{l}\text { Depth of ISS in } \\
\text { organization }\end{array}$ & Doherty and Fulford (2006) \\
\hline \multirow[t]{2}{*}{$\begin{array}{l}\text { Absorptive } \\
\text { capacity for ISS }\end{array}$} & & $\begin{array}{l}\text { Personnel competence } \\
\text { needed to implement } \\
\text { ISS }\end{array}$ & $\begin{array}{l}\text { Johnston and Warkentin } \\
(2010) \\
\text { Lee and Larsen (2009) }\end{array}$ \\
\hline & & $\begin{array}{l}\text { Financial resources } \\
\text { needed to implement } \\
\text { ISS }\end{array}$ & $\begin{array}{l}\text { Gupta and Hammond (2005) } \\
\text { Johnson (2009) } \\
\text { Lee and Larsen (2009) }\end{array}$ \\
\hline
\end{tabular}

which ISS security is intertwined with organizational strategy (Liang et al., 2007;

Massetti \& Zmud, 1996). Liang et al. developed a four-item reflective scale for 
absorptive capacity. However, using criteria from Petter et al. (2007), the scale was determined to be improperly specified as reflective. The four-item scale for absorptive capacity should have been specified as formative. Only two items from the scale could be modified to measure absorptive capacity for ISS in an organization. A two-item formative scale measured absorptive capacity.

\subsection{Summary}

This study adopted neo-institutional theory to examine how external influences motivate senior managers to participate in ISS by examining coercive, mimetic and normative mechanisms (DiMaggio \& Powell, 1983; Hu et al., 2007; Liang et al., 2007). The research method for this study was survey research. Survey research is appropriate for correlational studies in IS research (Bjorck, 2004; Mishra \& Agarwal, 2009; Sekaran \& Bougie, 2010; Siponen \& Willison, 2005; Straub, 1989; Teo et al., 2003; Xue et al., 2010).

The required sample size was 150 . A sample size of 150 reliably detects strong, moderate, and no effect sizes; but does not have sufficient power to detect weak effect sizes (Goodhue et al., 2006). This was appropriate for exploratory research (Hair et al., 2011). Data collection was conducted through an online survey. This research extended earlier IS and ISS research using surveys (Hu et al., 2007; Liang et al., 2007; Teo et al., 2003), but was adapted as an online survey. The tailored design method (Dillman, 1999) was used to attempt to achieve a $70 \%$ response rate (Sivo, Saunders, Chang, \& Jiang, 2006). 


\section{Chapter 4}

\section{Results}

\subsection{Introduction}

Chapter 4 is organized in four sections. Section 4.2 describes the data analysis method, while Section 4.3 explains the findings. Section 4.4 summarizes the chapter.

\subsection{Data Analysis}

Researchers should determine how to handle mixed formative and reflective constructs a priori to data collection (Petter et al., 2007). Component-based SEM, or Partial Least Squares (PLS), is recommended for formative and mixed models (Chin, 1998a; Petter et al., 2007). PLS is also recommended for exploratory research (Gefen \& Rigdon, 2011). This study is both exploratory research and uses a model with formative and reflective constructs, and therefore PLS is appropriate. The exogenous and dependent constructs are formative. The two mediating constructs are reflective. Six criteria are recommended for evaluating formative constructs (Cenfetelli \& Bassellier, 2009):

1) Examine for multicollinearity

2) Evaluate the number of indicators for each construct

3) Examine for co-occurrence of negative indicator weights 
4) Evaluate absolute and relative contributions made by indicators

5) Evaluate nomological network effects

6) Determine if PLS or covariance-based SEM best meets the research needs.

Evaluation includes testing the measurement and structural models (Diamantopoulos \& Winklhofer, 2001; Hair et al., 2011).

The measurement model was evaluated by examining multicollinearity, indicator weight, indicator significance, and convergent validity (Hair et al., 2011; Kock, 2012). Multicollinearity between indicators can cause unstable indicator weights and is not desired in formative constructs (Cenfetelli \& Bassellier, 2009; Gefen \& Rigdon, 2011; Hair et al., 2011). Indicators with a variance inflation factor (VIF) greater than 5.00 should be evaluated to determine if there is a conceptual overlap (Bagozzi, 2011; Cenfetelli \& Bassellier, 2009). Standards for acceptable VIF vary. Diamantopoulos and Siguaw (2006) recommend a VIF of 3.33, while Mathieson, Peacock, and Chin (2001) recommend 10.00. Even IS researchers lack agreement. Some IS researchers recommend 3.33 as the standard for formative indicators (Petter et al., 2007), and others recommend 10.00 (Mackenzie, Podsakoff, \& Podsakoff, 2011; Mathieson et al., 2001). Kock and Lynn (2012) argue that regression algorithms used in PLS minimize collinearity inflation to typically provide VIF values less than 2.00, and therefore support the standard of 3.33. This research used a VIF threshold of 3.33 (Diamantopoulos \& Siguaw, 2006; Kock \& Lynn, 2012; Petter et al., 2007). One indicator should be removed where conceptual overlap is found and removing the indicator does not alter the conceptual meaning of the construct (Cenfetelli \& Bassellier, 2009). An examination of how to improve the measurement is needed if removing the indicator would alter the conceptual meaning of 
the construct (Cenfetelli \& Bassellier, 2009). Evaluation of the structural model can continue if indicators with multicollinearity are retained (Cenfetelli \& Bassellier, 2009). An indicator should be removed when there is overlap and correlation is high. Indicators with high VIFs should be retained when they are conceptually important, when their weight is significant, or when removing the indicators results in a major reduction in the number of indicators (Kock, 2012).

Greater numbers of indicators for a formative construct increases the likeliness that some indicators will have low or nonsignificant weights (Cenfetelli \& Bassellier, 2009). Indicators were evaluated for weighting (Cenfetelli \& Bassellier, 2009).

Constructs with large numbers of indicators where some of those indicators have weights with a significance level ( $\rho$-value) greater than .05 were examined (Hair et al., 2011; Kock, 2010; Petter et al., 2007). Indicators that have low relative significance (weight) but high absolute significance (loading) are considered absolutely important, but relatively unimportant (Cenfetelli \& Bassellier, 2009). Indicators with low relative significance and high absolute significance were evaluated for theoretical relevance and overlap (Cenfetelli \& Bassellier, 2009). Standardized loading for each indicator should be higher than .70 (Hair et al., 2011). Indicators with standardized loading less than .40 should be removed if the weight is also nonsignificant (Cenfetelli \& Bassellier, 2009; Hair et al., 2011). Convergent validity is good when the responses to the question are understood by the participants in the same way they were intended (Hair, Anderson, \& Tatham, 1987; Hair, Black, Babin, \& Anderson, 2010). Convergent validity was acceptable when $\rho$-values associated with indicator loadings were lower than .05 and loadings were equal to or greater than .5 (Hair et al., 1987, 2010). 
The structural model was evaluated by examining $R^{2}$ values, path coefficients, and heterogeneity (Hair et al., 2011). $R^{2}$ values describe the amount of variance that can be explained by the exogenous constructs. Endogenous construct $R^{2}$ values of $.75, .50$, and .25 were considered substantial, moderate, and weak, respectively (Hair et al., 2011). The effect independent constructs have on dependent constructs should be reported (Hair et al., 2011; Ringle et al., 2012). This study examined the effect size and the $R^{2}$ values (Ringle et al., 2012).

Bootstrapping and jackknifing resampling methods can be used in PLS (Fornell \& Bookstein, 1982; Gefen et al., 2000; Petter et al., 2007; Ringle et al., 2012). Resampling methods and the PLS-SEM software application used should be reported (Ringle et al., 2012; Sarstedt, Henseler, \& Ringle, 2011). Bootstrapping and resampling of 5,000 is recommended for IS research using PLS (Chin, Marcolin, \& Newsted, 2003; Hair et al., 2011; Kock, 2012). This study used WarpPLS 4.0. However, WarpPLS limits bootstrapping resampling to 999 so analysis was done with bootstrapping with resampling of 999. Path weights with $\rho$-values less than .05 were considered valid (Hair et al., 2011; Kock, 2010; Petter et al., 2007).

The structural model was examined for heterogeneity (Ringle et al., 2012) using multi-group analysis (Kock, 2014). Heterogeneity occurs when members or groups within the population are subject to different models or different parameters within the same model (Gefen \& Rigdon, 2011). This study examined for and detected heterogeneity (Gefen \& Rigdon, 2011; Hair et al., 2011; Ringle et al., 2012). The source of heterogeneity cannot be fully assessed a priori, therefore heterogeneity was tested using common demographic variables (Hair et al., 2011). This study assessed 
heterogeneity on the basis of respondants' industry, firm size, and industry regulatory requirements.

Constructs should be assessed for nomological networks and portability (Cenfetelli \& Bassellier, 2009). Although some variation in indicator weight is expected, consistency is necessary to support portability and generalizability (Cenfetelli \& Bassellier, 2009). Indicator weights were compared to prior studies where a construct has been used (Cenfetelli \& Bassellier, 2009). The exogenous constructs have been used in two prior studies (Liang et al., 2007; Teo et al., 2003), and the endogenous constructs have been used in one prior study (Liang et al., 2007). Results from this study were compared to prior studies.

Cronbach's alpha (Cronbach, 1951) and composite reliability (Fornell \& Larcker, 1981) are recommended for assessing reliability of reflective constructs (Nunnally \& Bernstein, 1994; Ringle et al., 2012). Cronbach's alpha or composite reliability scores should exceed 0.70 (Fornell \& Larcker, 1981). Reliability of reflective constructs were evaluated using Cronbach's alpha and composite reliability. Convergent validity of reflective constructs was assessed using average variance extracted (AVE) (Fornell \& Larcker, 1981). Convergent validity is acceptable when AVE is greater than 0.5 (Fornell \& Larcker, 1981). Table 4.1 summarizes data analysis criteria.

The possibility of common method bias should be assessed prior to data collection (Williams, Edwards, \& Vandenberg, 2003). Common method bias can be controlled by procedural and statistical remedies (Podsakoff, MacKenzie, Lee, \& Podsakoff, 2003). Temporal and methodological separation techniques were used to minimize effects from 
common method bias (Podsakoff et al., 2003). Enns et al. (2003) and Liang et al. (2007) employed methodological separation techniques to reduce potential common method

Table 4.1

Data Analysis Criteria

\begin{tabular}{ll}
\hline Criteria & Standard \\
\hline Multicollinearity & VIF $\leq 3.33$ \\
Indicator weight & $\rho$-value $<.05$ \\
Indicator standardized loading & Standardized loading $\geq .5$ \\
Path weight & $\leq 0.05$ \\
$\mathrm{R}^{2}$ and effect size & Substantial effect size if $\boldsymbol{R}^{2} \geq .75$ \\
& Moderate effect size if $\boldsymbol{R}^{2} \geq .5$ and $<.75$ \\
& Weak effect size if $\quad \boldsymbol{R}^{2} \geq .25$ and $<.5$ \\
Reliability of reflective constructs & No effect if $\quad \boldsymbol{R}^{2}<.25$ \\
& Cronbach's alpha $\geq .7$, or \\
Convergent validity & Composite reliability $\geq .7$ \\
\hline
\end{tabular}

bias. A similar strategy was employed in this study. Liang et al. surveyed senior management about the exogenous constructs and senior management beliefs, but used secondary data to assess senior management participation and assimilation. Enns et al. utilized matched pair testing to separate evaluation of independent and dependent constructs. This study modified that approach by employing matched surveys (Enns et al., 2003; Johnson \& Lederer, 2010). Senior management was surveyed on the exogenous constructs and senior management beliefs (Liang et al., 2007); employees were surveyed on senior management participation in ISS and ISS assimilation (Enns et al., 2003; Liang et al., 2007).

Temporal separation was used to reduce the effects of common method bias (Podsakoff et al., 2003). Items for each construct were intermingled throughout the survey to reduce the likelihood respondents would recall their responses to a single 
construct, and therefore be influenced to respond similarly to other measurement items (Podsakoff et al., 2003). A second temporal separation strategy was to sequence survey items that measured effects before survey items that measured causes (Podsakoff et al., 2003). For example, survey items assessing senior management beliefs preceded items assessing exogenous constructs in the senior management survey. In the employee survey, items assessing ISS assimilation preceded items assessing senior management participation in ISS.

Effects of common method bias were evaluated using statistical tests (Enns et al., 2003; Liang et al., 2007; Podsakoff et al., 2003). Harman's one-factor test, and more recently, confirmatory factor analysis are commonly used to evaluate the impact of common method bias (Podsakoff et al., 2003; Podsakoff \& Organ, 1986). However, Podsakoff et al. (2003) noted limitations with Harman's one-factor test and confirmatory factor analysis, noting Harman's one-factor test only detects common method bias, but does not control for bias. Nonetheless, Harman's one-factor test is suitable for common method bias detection (Podsakoff et al., 2003). Multiple methods factor analysis is recommended as an alternative to control for common method bias (Podsakoff et al., 2003). Harman's one-factor testing was applied to detect common method bias, and multiple methods factor analysis using PLS was used to statistically control for common method bias (Liang et al., 2007; Podsakoff et al., 2003; Podsakoff \& Organ, 1986). Both statistical processes demonstrated low risk of common method bias.

A high nonresponse rate could indicate nonresponse bias or self-selection bias (Gefen \& Rigdon, 2011; Shmueli \& Koppius, 2011). Although a response rate of 55\% can achieve statistically reliable results with a significance level of .05 , the required 
sample size is 1,000 (Sivo et al., 2006). An alternative approach is to achieve a higher response rate with a smaller sample (Sivo et al., 2006). A response rate of $70 \%$ is recommended to achieve a significance level of .05 with a sample size of 70 (Sivo et al., 2006). This research employed the tailored design method (Dillman, 1999) to attempt to achieve a response rate of $70 \%$. A pilot study that did not employ the tailored design method achieved a 57\% response rate (Tejay \& Barton, 2013), so the higher response rate of $70 \%$ was considered attainable using the tailored design method. However, the $70 \%$ response rate was not achieved.

\subsection{Findings}

A response rate of $49.5 \%$ was achieved during the study. Invitations were sent to 105 organizations, 58 organizations submitted responses to both surveys. An additional 11 organizations responded to one of the two surveys, and therefore were not counted as complete responses. The senior management survey collected data for the exogenous constructs and senior management belief. Responses to the senior management survey provided useful data for understanding $\mathrm{H} 1$ and $\mathrm{H} 2$, and were therefore included in data analysis. The employee survey collected data on senior management participation and ISS assimilation. Responses to the employee survey without a matching response to the senior management survey were useful for measuring H6. One organization responded to the employee survey only. That response was used during data analysis.

The surveys used a five-point Likert scale. Employees were given a sixth option of "Do Not Know" for survey questions on the indicators to the senior management participation construct. Eleven respondents to the employee survey answered "Do Not Know" to all questions for senior management participation. Those responses were 
omitted from data analysis. Instances where employees responded "Do Not Know" to some, but not all questions, were used in data analysis by evaluating "Do Not Know" responses as null entries. A total of 167 matched tuples were received, while 148 matched tuples were used in data analysis. Of those, only 97 tuples had usable entries to every question to the senior management participation construct. Employees also reported higher than expected trends of senior management participation and ISS assimilation. Reported senior management participation and ISS assimilation did not vary significantly by industry, organization size, or absorptive capacity. Although employee responses may accurately indicate senior management participation and ISS assimilation, it may also

Table 4.2

Industry Distribution

\begin{tabular}{lcc}
\hline Industry & Frequency & Percentage \\
\hline Business Development & 5 & $8 \%$ \\
Construction & 4 & $7 \%$ \\
Energy & 1 & $2 \%$ \\
Entertainment and Hospitality & 4 & $7 \%$ \\
Financial and Banking & 5 & $10 \%$ \\
Government & 1 & $2 \%$ \\
Healthcare & 2 & $3 \%$ \\
Higher Education & 2 & $3 \%$ \\
Manufacturing & 3 & $5 \%$ \\
Non-Profit & 6 & $10 \%$ \\
Professional Service & 12 & $20 \%$ \\
Real Estate and Development & 2 & $3 \%$ \\
Religious & 1 & $2 \%$ \\
Retail & 4 & $7 \%$ \\
Technology & 6 & $10 \%$ \\
Transportation & 2 & $3 \%$ \\
\hline
\end{tabular}


indicate employee respondents were unwilling or unable to evaluate senior management participation in ISS.

Three strategies were employed to test for nonresponse bias since the $70 \%$ response rate was not attained: (a) comparison of demographic and economic differences, (b) comparison of early and late response differences, and (c) weighting adjustments (Sivo et al., 2006, p. 362). Invitations to participate were staggered over the data collection period. Non-response rates and time to complete the surveys were consistent across the study period. Size and industry of participating organizations were similar to organizations that did not respond. Late responding organizations were demographically similar to early responding organizations. Notably, organizations that participated consistently responded within 60 days of request, and with no more than 3 follow-ups. Organizational demographics were collected from participants and used to evaluate heterogeneity based on organization size, industry, and whether or not the industry has significant information security regulatory requirements. Tables 4.2, 4.3, 4.4, and 4.5 summarize the demographics of the participating organizations.

Table 4.3

Number of Employees Distribution

\begin{tabular}{lcc}
\hline Industry & Frequency & Percentage \\
\hline$\leq 10$ & 18 & $30 \%$ \\
$11-100$ & 24 & $40 \%$ \\
$101-1,000$ & 8 & $13.3 \%$ \\
$1,001-2,000$ & 5 & $8.3 \%$ \\
$>2,000$ & 5 & $8.3 \%$ \\
\hline
\end{tabular}


Table 4.4

Industries Subject to Information Security Regulation

Distribution - Estimated by Researcher

\begin{tabular}{lcc}
\hline Industry & Frequency & Percentage \\
\hline $\begin{array}{l}\text { Subject to Significant } \\
\text { Regulation }\end{array}$ & 12 & $20 \%$ \\
$\begin{array}{l}\text { Not Subject to Significant } \\
\text { Regulation }\end{array}$ & 48 & $80 \%$ \\
\hline
\end{tabular}

Table 4.5

Industries Subject to Information Security Regulation

Distribution - Reported by Participants

\begin{tabular}{lcc}
\hline Industry & Frequency & Percentage \\
\hline $\begin{array}{l}\text { Subject to Significant } \\
\text { Regulation }\end{array}$ & 28 & $47 \%$ \\
$\begin{array}{l}\text { Not Subject to Significant } \\
\text { Regulation }\end{array}$ & 32 & $53 \%$ \\
\hline
\end{tabular}

Heterogeneity was examined by separating responses by demographic categories and performing PLS analysis on the subsets. Specifically, comparisons between the sets in Table 4.6 were completed. The results indicate heterogeneity based on organizational demographics. The results are discussed in multi-group analysis and shown in Table 4.10.

Table 4.6

Demographic Factors for Heterogeneity Tests

\begin{tabular}{lll}
\hline Factor & Set $1 \quad$ Set 2 \\
\hline Industry & $\begin{array}{l}\text { Banking and Financial } \\
\text { Technology } \\
\text { Professional Services }\end{array}$ & All others \\
$\begin{array}{l}\text { Number of Employees } \\
\begin{array}{l}\text { Industry Regulation } \\
\text { (Researcher assessment) }\end{array}\end{array}$ & $\begin{array}{c}\text { Significantly regulated } \\
\begin{array}{l}\text { Industry Regulation } \\
\text { (Participant assessment) }\end{array}\end{array}$ & Not significantly regulated \\
\hline
\end{tabular}


Indicators were first evaluated for multicollinearity. Table 4.7 summarizes VIF, loading, and weighting significance for each indicator. NORM2, NORM3, MIM2, MIM4, and ASSIM2 had VIFs greater than 3.33. MIM2 was the only indicator with a VIF greater than 5. Those indicators were examined for conceptual overlap (Cenfetelli \& Bassellier, 2009). NORM2, NORM3, MIM2, and MIM4 are all conceptually different. ASSIM2 is also conceptually unique, but may appear similar to ASSIM1. ASSIM1 measures ISS across business processes while ASSIM2 measures ISS in functional areas. These concepts may not appear different if the reader does not evaluate the survey questions carefully. ASSIM2 was therefore removed from the construct and PLS analysis run again. Removing ASSIM2 did not effect path weights or $R^{2}$, so ASSIM2 was reported in the findings.

Standardized loadings for all indicators were greater than .5 and $\rho$-values were significant, as shown in Table 4.7. NORM4 and SMB3 had $\rho$-values $<0.01$. All other indicators had $\rho$-values $<0.001$. Indicator loadings were consistent with similar constructs in prior studies, demonstrating satisfactory nomological network effects (Cenfetelli \& Bassellier, 2009). Cross-loading was checked by verifying loading for each indicator was greatest on its specified construct. Cross-loading was satisfactory, with one exception. NORM4 loading was greater with COER than NORM. NORM4 measured senior management's exposure to media reports about ISS. Cross-loading might be explained by the perception of media reports as public or customer pressures, rather than normative pressures. NORM4 requires more examination to determine if either the instrument can be improved or if the indicator should be part of the coercive construct. The model demonstrated sufficient discriminant validity. 
Table 4.7

Normalized Cross-Loadings

\begin{tabular}{|c|c|c|c|c|c|c|c|c|c|}
\hline Indicator & NORM & MIM & COER & SMB & SMP & ASSIM & AbsCap & $\rho$-value & VIF \\
\hline NORM1 & 0.760 & 0.207 & -0.364 & -0.065 & 0.106 & 0.018 & 0.008 & $<0.001$ & 2.241 \\
\hline NORM2 & 0.692 & -0.039 & -0.010 & 0.089 & 0.026 & 0.010 & 0.022 & $<0.001$ & 4.952 \\
\hline NORM3 & 0.704 & -0.174 & 0.0186 & 0.026 & 0.078 & -0.124 & -0.038 & $<0.001$ & 3.706 \\
\hline NORM4 & 0.524 & -0.073 & 0.966 & -0.045 & -0.130 & -0.017 & 0.147 & $<0.01$ & 1.069 \\
\hline MIM1 & 0.189 & 0.675 & -0.031 & -0.203 & -0.101 & 0.060 & -0.155 & $<0.001$ & 1.949 \\
\hline MIM2 & 0.074 & 0.745 & -0.007 & -0.068 & -0.014 & -0.024 & 0.006 & $<0.001$ & 5.561 \\
\hline MIM3 & -0.022 & 0.752 & -0.138 & 0.118 & -0.099 & 0.114 & -0.020 & $<0.001$ & 2.227 \\
\hline MIM4 & 0.189 & 0.770 & -0.031 & -0.203 & -0.101 & 0.060 & -0.151 & $<0.001$ & 4.941 \\
\hline COER1 & 0.533 & -0.179 & 0.616 & 0.189 & 0.188 & -0.334 & 0.071 & $<0.001$ & 1.492 \\
\hline COER2 & 0.172 & -0.057 & 0.615 & 0.092 & -0.159 & 0.219 & 0.421 & $<0.001$ & 1.714 \\
\hline COER3 & 0.092 & 0.040 & 0.667 & 0.047 & 0.337 & -0.231 & -0.172 & $<0.001$ & 1.440 \\
\hline COER4 & -0.144 & 0.048 & 0.691 & -0.044 & -0.175 & 0.106 & -0.033 & $<0.001$ & 2.340 \\
\hline COER5 & 0.357 & 0.410 & 0.727 & 0.362 & 0.023 & 0.171 & 0.104 & $<0.001$ & 2.223 \\
\hline SMB1 & 0.159 & 0.201 & 0.460 & 0.807 & 0.067 & 0.225 & 0.127 & $<0.001$ & $\mathrm{n} / \mathrm{a}$ \\
\hline SMB2 & 0.312 & 0.388 & 0.444 & 0.708 & 0.136 & 0.141 & -0.019 & $<0.001$ & $\mathrm{n} / \mathrm{a}$ \\
\hline SMB3 & 0.090 & 0.169 & 0.208 & 0.947 & 0.025 & -0.091 & 0.067 & $<0.01$ & $\mathrm{n} / \mathrm{a}$ \\
\hline SMP1 & -0.013 & -0.031 & -0.042 & 0.030 & 0.879 & 0.469 & 0.057 & $<0.001$ & $\mathrm{n} / \mathrm{a}$ \\
\hline SMP2 & 0.037 & 0.015 & 0.001 & 0.060 & 0.876 & 0.462 & 0.123 & $<0.001$ & $\mathrm{n} / \mathrm{a}$ \\
\hline SMP3 & 0.054 & 0.049 & 0.064 & 0.128 & 0.850 & 0.493 & 0.082 & $<0.001$ & $\mathrm{n} / \mathrm{a}$ \\
\hline SMP4 & 0.118 & 0.111 & 0.154 & 0.108 & 0.752 & 0.603 & 0.091 & $<0.001$ & $\mathrm{n} / \mathrm{a}$ \\
\hline SMP5 & 0.049 & 0.047 & 0.077 & 0.127 & 0.875 & 0.424 & 0.012 & $<0.001$ & $\mathrm{n} / \mathrm{a}$ \\
\hline SMP6 & -0.035 & 0.004 & -0.006 & 0.115 & 0.892 & 0.402 & -0.012 & $<0.001$ & $\mathrm{n} / \mathrm{a}$ \\
\hline SMP7 & 0.065 & -0.024 & 0.028 & 0.159 & 0.841 & 0.500 & 0.112 & $<0.001$ & $\mathrm{n} / \mathrm{a}$ \\
\hline ASSIM1 & 0.122 & 0.065 & 0.262 & 0.213 & 0.413 & 0.822 & 0.089 & $<0.001$ & 1.479 \\
\hline ASSIM2 & 0.128 & 0.053 & 0.218 & 0.166 & 0.442 & 0.808 & 0.131 & $<0.001$ & 4.645 \\
\hline ASSIM3 & 0.204 & 0.151 & 0.086 & 0.177 & 0.453 & 0.799 & 0.146 & $<0.001$ & 2.479 \\
\hline ASSIM4 & 0.166 & 0.042 & 0.168 & 0.104 & 0.514 & 0.806 & 0.120 & $<0.001$ & 2.360 \\
\hline ASSIM5 & 0.235 & 0.109 & 0.137 & 0.085 & 0.436 & 0.832 & 0.098 & $<0.001$ & 2.135 \\
\hline AbsCap1 & 0.217 & 0.143 & 0.212 & 0.015 & 0.082 & 0.062 & 0.935 & $<0.001$ & 1.438 \\
\hline AbsCap2 & 0.411 & 0.204 & 0.325 & 0.096 & 0.053 & 0.174 & 0.796 & $<0.001$ & 1.438 \\
\hline
\end{tabular}


Table 4.8

Correlations among Major Constructs

\begin{tabular}{|c|c|c|c|c|c|c|c|}
\hline Construct & NORM & MIM & COER & SMB & SMP & ASSIM & AbsCap \\
\hline NORM & 0.801 & & & & & & \\
\hline MIM & $0.531 * * *$ & 0.858 & & & & & \\
\hline COER & $0.664 * * *$ & $0.575 * * *$ & 0.770 & & & & \\
\hline SMB & $0.278 * * *$ & $0.358 * * *$ & $0.534 * * *$ & 0.731 & & & \\
\hline SMP & 0.042 & 0.027 & 0.042 & 0.117 & 0.832 & & \\
\hline ASSIM & $0.205^{*}$ & 0.097 & $0.222 * *$ & $0.182 *$ & $0.557 * * *$ & 0.790 & \\
\hline AbsCap & $0.374 * * *$ & $0.205^{*}$ & $0.318 * * *$ & 0.068 & 0.077 & 0.143 & 0.881 \\
\hline
\end{tabular}

Correlation among constructs was examined. Table 4.8 reports correlation among constructs. Although the model demonstrated sufficient discriminant validity, co-linearity was detected between constructs NORM and MIM, NORM and COER, NORM and SMB, NORM and AbsCap, MIM and COER, COER and SMB, COER and AbsCap, and SMP and ASSIM, suggesting the results may not be reliable for constructs NORM, MIM, COER, SMP and ASSIM.

Path weights were examined between constructs. Figure 4.1 shows H2, H5, and H6 were supported. H1, H3, H4 and the moderating construct absorptive capacity were not supported. $R^{2}$ was low for SMB, SMP, and ISS ASSIM. Weak effect from the exogenous constructs was found for SMB and ISS ASSIM, while no effect was found for SMP. This suggests the exogenous constructs only explained $22 \%$ of the variance for SMB and $29 \%$ of the variance for ISS ASSIM. The exogenous constructs did not explain variance in SMP. Therefore, the results may not be reliable. 


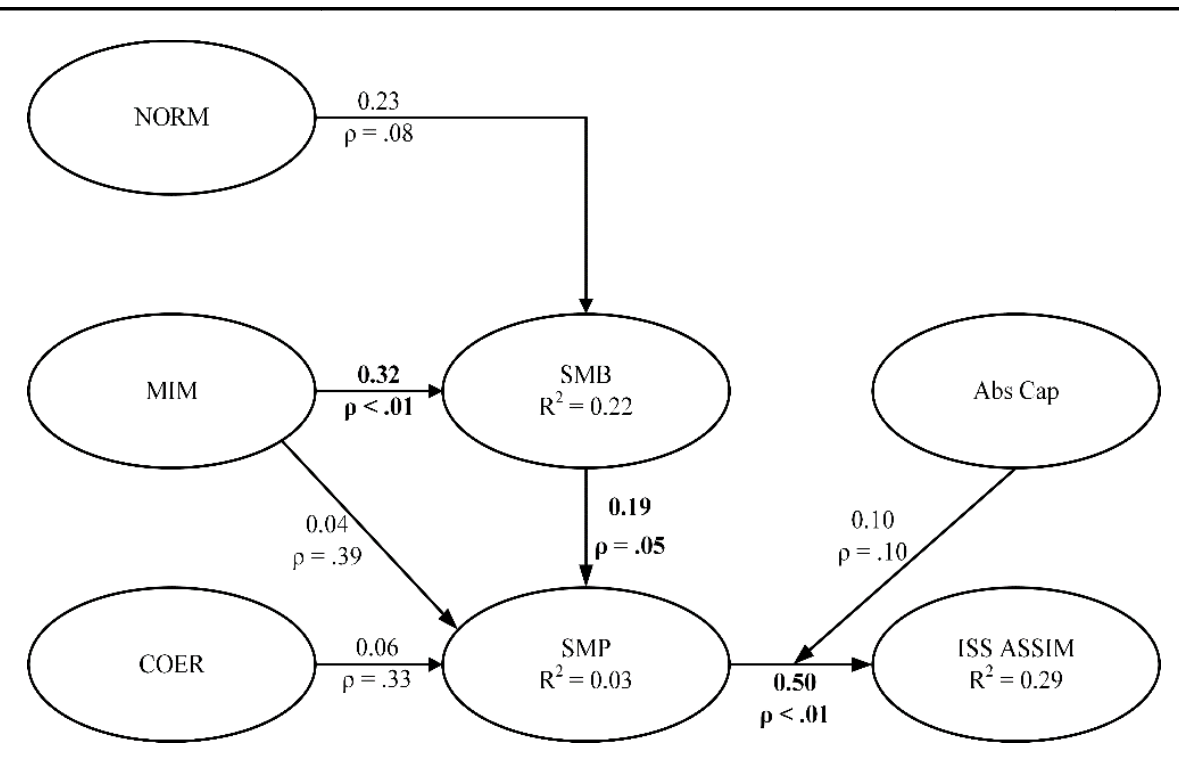

Figure 4.1. PLS Analysis of Results

Reliability of reflective constructs was assessed with Cronbach's alpha and composite reliability. The model included two reflective constructs, SMB and SMP. Composite reliability was 0.768 for SMB and 0.925 for SMP. Cronbach's alpha was 0.549 for SMB and 0.925 for SMP. Reliability is determined satisfactory based on the composite reliability scores exceeding 0.70 . AVE was 0.534 for SMB and 0.692 for SMP, demonstrating satisfactory validity.

Global validation of a model can be assessed using $x^{2}$ and related fit indicators in covariance-based SEM, but not in PLS (Guenzi, Georges, \& Pardo, 2009; Lane \& Lum, 2011; Tenenhaus, Vinzi, Chatelin, \& Lauro, 2005). A Goodness-of-Fit (GoF) measurement is recommended as an operational solution to validating a PLS model globally (Guenzi et al., 2009). GoF can be calculated as the geometric mean of the average communality and the average $R^{2}$ (Tenenhaus et al., 2005). Kock (2013) argues the AVE for each construct can be used to calculate the GoF, rather than the average 
communality, because AVE is the same as communality in PLS path modeling (Wetzels, Odekerken-Schroder, \& van Oppen, 2009). Therefore, WarpPLS calculates Tenenhaus's GoF as the square root of the product of average AVE and average $R^{2}$ (Kock, 2013). GoF thresholds are small $=0.1$, medium $=0.25$, and large $=0.36($ Kock, 2013; Lane $\&$ Lum, 2011; Wetzels et al., 2009). The Tenenhaus GoF $=0.364$, demonstrating large effect size.

Harman's one-factor test was conducted to test for common method bias using SPSS version 22. All variables were entered into a factor analysis and examined to determine the number of factors needed to explain more than $50 \%$ of the variance (Podsakoff \& Organ, 1986). Results showed only $28 \%$ of variance could be attributed to a single factor and that three factors were required to explain more than $50 \%$ of variance, demonstrating a reduced risk of common method bias. Multiple methods factor analysis was also conducted in SPSS 22. Table 4.9 shows results from multiple methods factor

Table 4.9

Percent of Variance from Multiple Methods Factor Analysis

\begin{tabular}{lcccc} 
Component & Varimax & Equamax & Promax & Direct Oblimin \\
\hline 1 & 28.051 & 28.051 & 28.051 & 28.051 \\
2 & 20.653 & 20.653 & 20.653 & 20.653 \\
3 & 6.706 & 6.706 & 6.706 & 6.706 \\
4 & 5.632 & 5.632 & 5.632 & 5.632 \\
5 & 5.160 & 5.160 & 5.160 & 5.160 \\
6 & 4.178 & 4.178 & 4.178 & 4.178 \\
7 & 3.833 & 3.833 & 3.833 & 3.833 \\
8 & 3.713 & 3.713 & 3.713 & 3.713 \\
9 & 3.116 & 3.116 & 3.116 & 3.116 \\
10 & 2.514 & 2.514 & 2.514 & 2.514 \\
11 & 2.232 & 2.232 & 2.232 & 2.232 \\
12 & 1.750 & 1.750 & 1.750 & 1.750 \\
13 & 1.622 & 1.622 & 1.622 & 1.622 \\
14 & 1.420 & 1.420 & 1.420 & 1.420 \\
\hline
\end{tabular}


analysis. Results were consistent for every method and supported conclusions from the Harman's one-factor test. Analysis demonstrates low risk of common method bias.

Multi-group analysis tests differences between two data sets when they are applied to the same model. This study examined differences between data sets based on four demographic characteristics: firm size, industry, industry regulatory requirements as reported by the participants, and industry regulatory requirements as predicted by the researcher. Two testing methods were used, the pooled standard error and Satterthwaite

Table 4.10

Multi-Group Analysis Results

\begin{tabular}{|c|c|c|c|c|c|c|c|}
\hline Demographic & Hypothesis & $\beta_{1}$ & $\mathrm{SE}_{1}$ & $\beta_{2}$ & $\mathrm{SE}_{2}$ & $\begin{array}{l}\text { Pooled } \\
\text { Standard }\end{array}$ & Satterthwaite \\
\hline \multirow{6}{*}{$\begin{array}{l}\text { Firm Size - Number } \\
\text { of Employees }\end{array}$} & H1 & 0.291 & 0.293 & 0.133 & 0.221 & 0.358 & 0.334 \\
\hline & $\mathrm{H} 2$ & 0.365 & 0.127 & 0.732 & 0.372 & 0.135 & 0.137 \\
\hline & H3 & -0.103 & 0.213 & -0.113 & 0.257 & 0.488 & 0.488 \\
\hline & $\mathrm{H} 4$ & -0.152 & 0.131 & 0.199 & 0.214 & 0.091 & 0.089 \\
\hline & H5 & 0.161 & 0.165 & 0.091 & 0.221 & 0.397 & 0.400 \\
\hline & H6 & 0.651 & 0.129 & 0.522 & 0.118 & 0.227 & 0.220 \\
\hline \multirow{6}{*}{ Industry } & H1 & 0.063 & 0.121 & 0.656 & 0.316 & 0.017 & 0.038 \\
\hline & $\mathrm{H} 2$ & 0.792 & 0.210 & 0.204 & 0.240 & 0.040 & 0.037 \\
\hline & H3 & -0.109 & 0.147 & -0.163 & 0.212 & 0.416 & 0.417 \\
\hline & $\mathrm{H} 4$ & -0.049 & 0.131 & 0.023 & 0.181 & 0.373 & 0.374 \\
\hline & H5 & 0.127 & 0.166 & 0.281 & 0.198 & 0.284 & 0.276 \\
\hline & H6 & 0.710 & 0.073 & 0.692 & 0.111 & 0.444 & 0.446 \\
\hline \multirow{6}{*}{$\begin{array}{l}\text { Regulatory } \\
\text { Requirements - } \\
\text { Predicted by } \\
\text { Researcher }\end{array}$} & H1 & -0.267 & 0.298 & 0.226 & 0.339 & 0.145 & 0.138 \\
\hline & $\mathrm{H} 2$ & 0.356 & 0.101 & 0.517 & 0.164 & 0.217 & 0.202 \\
\hline & H3 & -0.247 & 0.278 & -0.052 & 0.137 & 0.150 & 0.168 \\
\hline & $\mathrm{H} 4$ & 0.060 & 0.155 & -0.127 & 0.172 & 0.216 & 0.210 \\
\hline & H5 & 0.202 & 0.149 & 0.125 & 0.175 & 0.373 & 0.369 \\
\hline & H6 & 0.747 & 0.070 & 0.672 & 0.106 & 0.289 & 0.278 \\
\hline \multirow{6}{*}{$\begin{array}{l}\text { Regulatory } \\
\text { Requirements - } \\
\text { Reported by } \\
\text { Participants }\end{array}$} & $\mathrm{H} 1$ & -0.267 & 0.298 & 0.228 & 0.312 & 0.125 & 0.127 \\
\hline & $\mathrm{H} 2$ & 0.356 & 0.101 & 0.293 & 0.433 & 0.443 & 0.444 \\
\hline & $\mathrm{H} 3$ & -0.247 & 0.278 & -0.171 & 0.259 & 0.420 & 0.421 \\
\hline & $\mathrm{H} 4$ & 0.060 & 0.155 & -0.250 & 0.282 & 0.167 & 0.169 \\
\hline & H5 & 0.202 & 0.149 & 0.096 & 0.268 & 0.364 & 0.365 \\
\hline & H6 & 0.747 & 0.070 & 0.424 & 0.109 & 0.007 & 0.007 \\
\hline
\end{tabular}


methods (Kock, 2014). Heterogeneity was detected in H1 and H2 in multiple demographic categories, including industry, firm size and regulatory requirements as reported by both the researcher and participants. Heterogeneity was also detected with $\mathrm{H} 4$ based on firm size and $\mathrm{H} 6$ based on participant reporting of regulatory requirements. Table 4.10 summarizes results from multi-group testing. A $\rho$-value threshold of less than 0.15 was used to determine heterogeneity (Kock, 2014).

Effect size was evaluated. Table 4.11 summarizes effect size for each path. Moderate effect size was demonstrated between SMP and ASSIM. MIM and COER showed no effect on SMP. All other relationships showed weak effect size. Based on the sample size, desired power level $(1-\beta=.80)$, significance level of $\alpha=.05$, and the high occurrence of weak effect size, it must be concluded that the results do not have sufficient effect size to be reliable.

Table 4.11

Effect Size of Independent Constructs on Dependent Constructs

\begin{tabular}{lccccccc}
\hline Construct & NORM & MIM & COER & SMB & SMP & ASSIM & AbsCap \\
\hline NORM & & & & & & \\
MIM & & & & & & \\
COER & & & & & & \\
SMB & $0.083^{* *}$ & $0.132^{* * *}$ & & & & $0.038^{* *}$ \\
SMP & & $0.001^{*}$ & $0.004^{*}$ & $0.035^{* * *}$ & & \\
ASSIM & & & & & $0.344^{* * * *}$ & \\
AbsCap & & & & & & \\
\hline$* * * *$ strong; *** moderate; ** weak; *no effect & & & & &
\end{tabular}


Table 4.12 summarizes the key statistical results and conclusions for the six hypotheses. Heterogeneity was detected with hypotheses $\mathrm{H} 1, \mathrm{H} 2, \mathrm{H} 4$, and $\mathrm{H} 6$ based on firm size, industry, or perceived existence of regulatory requirements. Three hypotheses were supported. H2, H5, and H6 had $\rho$-values $\leq .05$ and weak or moderate effect size. The $\rho$-value for H1 was greater than .05, and therefore was not supported. However, weak effect size was also detected with H1. Given the sample size, the study did not have the power to reliably detect results for weak effect size. Therefore, confirmatory research should be conducted before making conclusions on $\mathrm{H} 1, \mathrm{H} 2$, or H5.

Table 4.12

Summary of Key Statistical Results and Conclusions of Hypothesis Testing

\begin{tabular}{|c|c|c|c|c|c|c|}
\hline Test & $\mathrm{H} 1$ & $\mathrm{H} 2$ & H3 & $\mathrm{H} 4$ & H5 & H6 \\
\hline \multirow[t]{2}{*}{ Heterogeneity } & $\begin{array}{l}\text { Industry } \\
\text { Regulatory }\end{array}$ & $\begin{array}{l}\text { Firm size } \\
\text { Industry }\end{array}$ & & Firm size & & D onloto \\
\hline & & & None & & None & \\
\hline Path weight & 0.23 & 0.32 & 0.04 & 0.06 & 0.19 & 0.50 \\
\hline$\rho$-value & 0.08 & $<0.01$ & 0.39 & 0.33 & 0.05 & $<0.01$ \\
\hline Effect size & $0.083 * *$ & $0.132 * *$ & $0.001^{*}$ & $0.004 *$ & $0.035 * *$ & $0.344 * * *$ \\
\hline Supported & no & yes & no & no & yes & yes \\
\hline
\end{tabular}

\subsection{Summary}

Data analysis used SEM-PLS to evaluate the measurement model and test the hypotheses proposed in the research model. Data examination used six steps: 1) examined for multicollinearity, 2) evaluated the number of indicators for each construct, 3) examined for co-occurrence of negative indicator weights, 4) evaluated absolute and relative contributions made by indicators, 5) evaluated nomological network effects, and 6) determined if PLS or covariance-based SEM best meets the research needs. Data 
analysis also evaluated and controlled for common method bias. Analysis demonstrated low risk for common method bias.

This study proposed six hypotheses. The results supported H2, H5, and H6, while $\mathrm{H} 1, \mathrm{H} 3$, and $\mathrm{H} 4$ were not supported. However, effect size for the endogenous constructs SMB and ISS ASSIM were weak and no effect was detected with endogenous construct SMP, suggesting the results could be unreliable. Comparison of these results to prior studies show similar conclusions about reliability. For example, Liang et al. (2007) found support for four of six hypotheses. Similarly, Tejay and Barton (2013) found support for four of six hypotheses. Both Liang et al. and Tejay and Barton reported weak or no effect on endogenous constructs. The pilot study (Tejay \& Barton, 2013) suggested the constructs SMP and ISS ASSIM were closer to the criteria for moderate effect, and that SMB had no effect. The deficiencies noted in the pilot study were addressed by modifying the exogenous constructs related to SMB. An additional indicator was added to NORM. The larger sample size in this study was also expected to improve the variance detected in the endogenous constructs. However, the results of this study suggest the problem with effect size was not mitigated. Possible solutions will be addressed in Chapter 5. 


\section{Chapter 5}

\section{Conclusions}

\subsection{Introduction}

Chapter 5 is organized in five sections. Section 5.2 describes conclusions based on results of the study, and explains strengths, weaknesses, and limitations of the study. Section 5.3 discusses impacts this work has on ISS researchers and practitioners. Section 5.4 describes limitations and delimitations while section 5.5 provides recommendations for future research and addresses ways weaknesses in this study could be addressed. Section 5.6 summarizes this work.

\subsection{Conclusions}

Hypotheses H2, H5, and H6 were supported, while H1, H3, and H4 were not supported. The results indicate senior management beliefs regarding ISS influence their participation in ISS. This study held that governance is senior management's primary role in ISS. Therefore, it can be concluded senior management belief in ISS increases their participation in ISS governance. Senior management's participation in ISS governance influences ISS assimilation in organizations, supporting the long-held argument that senior management sponsorship is critical to successful ISS in organizations. This study found that senior management belief in ISS leads to greater ISS assimilation in organizations by increasing senior management participation in ISS governance. 
Therefore, ISS can be assimilated in organizations more effectively by understanding the factors that increase belief and participation in ISS by senior management.

This study attempted to explain the external factors that motivated senior management belief and participation in ISS, however results from the study only partially supported the hypotheses that external normative, mimetic, and coercive influences increased senior management belief and participation in ISS. The study found correlation between mimetic influences and senior management beliefs. Results suggest that mimetic influences increase senior management participation by increasing their belief in ISS, while normative and coercive influences had insignificant impact on either senior management belief or participation in ISS.

Several factors could explain these findings. First, the target population was small- and medium-sized organizations in multiple industries. One goal of the study was to examine ISS assimilation in organizations that do not have significant compliance requirements for ISS, and one way to achieve this objective was to include organizations from a broad range of industries. Sixteen industries were represented in the sample. Multi-group analysis demonstrated heterogeneity based on industry and industry related regulatory requirements. Interestingly, participants reported regulatory requirements for ISS in industries not expected to have significant regulatory requirements by the researcher. No difference was detected between participants based on industry or reported regulatory requirements for hypotheses directly related to coercive influences (H4), but heterogeneity was detected for hypotheses related to senior management belief ( $\mathrm{H} 1$ and H2). Heterogeneity is not a result of different experiences of the participants, but of 
different results on the research model as a result of demographic factors. This suggests either the model cannot be generalized or problems exist with the research method.

It was also noted that employees participating in the study selected the option "Do Not Know" at a high rate. Eleven percent of participating employees selected "Do Not Know" for every indicator of the SMP construct. As previously noted, this could be a result of the employees being reluctant to accurately report their observance of senior management's participation in ISS, insufficient knowledge or experience to evaluate senior management's participation in ISS, or disinterest to participate in the study. Considering the high incidence of "Do Not Know" responses and the heterogeneity detected with $\mathrm{H} 1$ and $\mathrm{H} 2$, it is possible variations in normative influences were significant enough to compromise the ability of participants to effectively participate in this study. This possibility is further supported by weak effect in the endogenous constructs and cross-loadings with indicator NORM4.

Mimetic influences were found to have significant correlation with senior management beliefs, but no direct correlation with senior management participation in ISS. This suggests senior management's observations and perceptions of successful ISS implementations in other organizations affects their belief system, and as a result increases their participation in ISS. Mimetic influences do have an effect on senior management participation in ISS, but are mediated by beliefs.

\subsection{Contribution to Research and Practice}

This study supported the hypotheses that greater senior management belief and participation in ISS led to greater ISS assimilation in organizations, but failed to explain 
the factors that influence senior management belief and participation in ISS.

Heterogeneity, high rates of unusable responses, and weak effect sizes suggest deficiencies existed in the research method.

For researchers, this study provides empirical evidence of the mediating role senior management has between external influences and ISS assimilation. Senior management's role was further explained by examining the relationship between ISS beliefs and ISS participation. Senior management participation in ISS was defined as ISS governance. Therefore, results from the study provide empirical evidence that senior management belief in ISS influences senior management participation in ISS governance, which increases ISS assimilation.

However, the study did not provide a robust explanation of how external influences motivate senior management to participate in ISS governance. Mimetic influences was the only external factor that correlated with senior management belief or participation. No further explanation was found between external influences and senior management belief or participation. Heterogeneity and weak effect sizes suggest deficiencies existed with the instrument or method, and that further research is required to understand the mediating role senior management has between external influences and ISS assimilation.

The findings with normative influences were noteworthy. Senior managers reported a generally high belief in ISS. However, external influences varied significantly. This suggests a factor that was not accounted for in the normative influences construct may exist. Since the normative influences construct is formative, this weakness could have significant effect on the ability of the construct to accurately measure normative 
influences. Future research should examine that construct to determine if it fully operationalizes the concept.

Findings from this study contradicted recent research. For example, Holgate and Hardy (2012) found evidence that should have supported H1 and H3, but those hypotheses were not supported in this study. Holgate and Hardy employed a different research method, using interviews instead of survey. Considering the multicollinearity detected between both measurement items and constructs in this study, this study could suggest that greater interaction is needed between subjects and researchers during data collection on this research.

This study shows that senior management belief in the value of ISS and participation in ISS directly contributes to ISS assimilation in the organization, and that external influences shape senior management's beliefs and practice. This finding highlights three contributions to practice. First, it reinforces the argument that IS and ISS managers need senior management support to ensure the effectiveness of ISS programs. Senior management participation in ISS is important, but their belief in ISS is equally important. IS and ISS managers should purposefully develop the understanding of ISS' business value and contributions to operations. Second, this study informs IS and ISS managers that senior managers are influenced by external factors, to include mimetic forces. IS and ISS managers within industries should look for opportunities to communicate their experiences and knowledge through industry groups and include requirements for ISS in partnerships. Third, government regulators and industry groups can increase senior management commitment in SMEs to ISS through not only regulations and mandates, but also mimetic mechanisms. Sharing information from 
benchmark industry and government organizations in ISS could foster the senior management participation needed to advance ISS within organizations and industries.

\subsection{Limitations and Delimitations}

This dissertation presented several inherent challenges. First, researchers consider ISS research to be inherently difficult because of the trust required between organizations and researchers (Kotulic \& Clark, 2004). Organizations are often unwilling to participate in ISS research due to the perceived risk of disclosing sensitive information about the organization's vulnerabilities and critical information (Kotulic \& Clark, 2004). This study had the potential to amplify that problem. The study collected data directly from senior management about the external influences they are exposed to and their beliefs in ISS. The study also collected information from their employees on senior management's participation in ISS and ISS assimilation throughout the organization. Although matched surveys are proposed as a method to reduce risk of common method bias (Enns et al., 2003), they introduce the possibility senior management may feel threatened that their employees might report less effective leadership in ISS than they would want to project. As a result, senior management may have been reluctant to authorize their organizations to participate in the study. This limitation was addressed through a priori and post hoc strategies (Dillman, 1999; Sivo et al., 2006).

Second, it was anticipated that many of the prospective participants would have very limited experience or knowledge is ISS, either individually or within their industries. This could have led to unreliable data collection, and ultimately, unreliable findings. Statistical analysis examined for sufficient fit of the structural and measurement models. 
Third, PLS-SEM was used for data analysis. Although PLS is well suited for this study, it also presents challenges. Construct specification is widely considered a problem in IS and ISS research (Jarvis, Mackenzie, \& Podsakoff, 2003, 2012; Petter, Rai, \& Straub, 2012; Petter et al., 2007). The model required thorough analysis to ensure the constructs were complete and specified correctly. A pilot study tested the instrument and measurement items (Tejay \& Barton, 2013). Results from Tejay and Barton were used to modify measurement items for the construct normative mechanisms for ISS. Data analysis also considered the possibility of bias and used statistical and procedural remedies to control for bias (Evermann \& Tate, 2011; Mackenzie et al., 2011; Petter et al., 2007; Podsakoff et al., 2003).

The sample size of 150 limits this study to detecting medium and large effects (Goodhue et al., 2006). This delimitation is appropriate for exploratory studies. A confirmatory study would be required to detect small effects prior to discarding the measurement items for the measurement items that do not demonstrate medium or large effect size. The potential for small effect size must be considered when evaluating this study's generalizability.

\subsection{Recommendations}

Limitations of this study include the weak effect of independent constructs on dependent constructs, weak effect size, multicollinearity between constructs, and heterogeneity. This study also found indications that employees were unable or unwilling to assess senior management participation in ISS, and that questionnaire survey may not be a suitable method for this research. Future research should address these limitations. It 
is possible the limitations with the structural model could be a reflection of limitations in the method.

The first recommendation is to consider different research methods. For example, since the possibility that participant knowledge and experience may have had negative effects on this study, future research might include employee education as a treatment in the study. Either quasi-experimental or design science research that includes an employee educational component could validate if user experience was a factor while mitigating the negative effects to the research effort from weak employee knowledge in ISS. Future research might also consider alternate data collection methods. For example, future research may replace self-reported surveys with researcher assessment, or assessment by an experienced third-party. Interviews are another option, and could enable researchers to identify and possibly address participant knowledge gaps during data collection.

The second recommendation is to address heterogeneity. Analysis showed heterogeneity based on multiple demographic criteria, including industry and regulatory requirements. Although it is possible heterogeneity could be explained by unreliability in the findings, future research should examine the effects industry and regulation have on the research model. This study was limited geographically to small- and medium-sized organizations in the central-southern United States. Future research may examine large organizations and expand the geographic population. Future research may also look at international organizations and at different cultures.

The last recommendation for researchers is to identify the sources of multicollinearity and weak effect size. A review of the constructs confirmed the conceptual uniqueness of the constructs and the indicators for each construct, yet there 
was strong evidence of multicollinearity. That problem could have manifested from several sources, such as the instrument or the participants' experience. A better understanding of these issues could help not only future research on this topic, but future research that uses questionnaire surveys or research that collects data from laypeople on complex or technical topics.

Results from this study can also be used to inform practitioners. Most importantly, it confirms findings from prior research that senior management participation is important to effective ISS, and that senior management belief in ISS is a precursor to participation. Although this study did not demonstrate that normative influences correlated to senior management belief in ISS, prior research supports the relationship between normative influences and belief. This study did find mimetic influences increased belief in ISS. The findings suggest that efforts to demonstrate how ISS benefits other organizations, or how other organizations use ISS to address risk could increase senior management belief in ISS, and ultimately improve their participation and assimilation of ISS across the organization. This study did not support the importance of senior management education, but prior research shows educating senior management on ISS increases their belief in ISS.

As previously noted, the normative influences construct may not be fully specified. It is possible additional indicators are needed. However, it is also possible the study relied on an inaccurate assumption that commonly available ISS education and training is appropriate for senior management. Most ISS education and training is targeted to either ISS experts, IS personnel, or users. The content appropriate for these groups may not be the correct content for senior management. Senior managers may 
respond differently if exposed to education and training more specific to their role.

Therefore, practitioners might consider developing executive-level ISS education and training as part of a strategy to build senior management support.

\subsection{Summary}

This study investigated how external influences motivate senior management commitment to ISS by examining the mediating role of senior management between external influences and ISS assimilation. The justification for this research was that senior management commitment is a key factor determining ISS success within organizations, yet there is insufficient understanding of the factors that motivate senior management to commit to ISS. Although ISS research has established senior management commitment leads to effective development, implementation, and compliance with ISS controls (Boss et al., 2009; Bulgurcu et al., 2010a; Da Veiga \& Eloff, 2007; Hu et al., 2007; McFadzean et al., 2006), there is insufficient understanding about the factors that motivate senior management to commit to ISS (Johnson, 2009).

Questionnaire survey was selected as the research method. The study population was a convenience sample of SMEs throughout south-central United States. Convenience sampling is appropriate for exploratory research. Data collection was through online survey, using matched pair questionnaire surveys to reduce the effects of common method bias. Enns et al. (2003) utilized matched pair surveys to reduce the risk of common method bias. This study employed a similar technique. The sample size was 167. A sample size of 167 reliably detects strong, moderate, and no effect sizes; but does not have sufficient power to detect weak effect sizes (Goodhue et al., 2006). 
The results indicate senior management beliefs regarding ISS influence their participation in ISS. This study held that governance is senior management's primary role in ISS. Therefore, it can be concluded senior management belief in ISS increases their participation in ISS governance. Senior management's participation in ISS governance influences ISS assimilation in organizations, supporting the long-held argument senior management sponsorship is critical to successful ISS in organizations. This study found senior management belief in ISS leads to greater ISS assimilation in organizations by increasing senior management participation in ISS governance. Therefore, ISS can be assimilated in organizations more effectively by understanding the factors that increase belief and participation in ISS by senior management.

However, the results had minimal impact advancing the understanding of how external influences impacted senior management belief and participation in ISS. Mimetic influences were found to positively influence senior management beliefs, but results did not support hypotheses related to normative or coercive influences. Weak effect of the exogenous constructs on the endogenous constructs suggests the results may be unreliable. The sources of these issues were not identified, but indications suggest they might be attributed to a knowledge gap of the study participants or an unwillingness of employees to rate senior management participation in ISS. 
Appendix A

Data Collection Instrument 


\section{Scale and Items}

\section{ISS Assimilation}

1. From your experience, what percentage of business processes in your organization have adopted information system security?

2. From your experience, what percentage of functional areas in your organization that have adopted information system security.

( 1 = strongly disagree; 5 = strongly agree)

3. Information system security is an important element of every business process in my organization.

4. The appropriate levels of information system security exist in every functional area in my organization.

5. Information system security aligns with the strategic goals of my organization.

Senior management belief (SMB) (1 = strongly disagree; $5=$ strongly agree) I believe:

1. Information system security has the potential to provide significant business benefits to our firm.

2. Improving information system security will create a significant competitive advantage for firms in our industry.

3. Information system security does NOT improve execution of business activities.

Senior management participation (SMP) $(1=$ strongly disagree; $5=$ strongly agree)

The senior management of my organization:

1. Articulates a vision for information system security.

2. Formulates a strategy to implement information system security.

3. Monitors feedback mechanisms to ensure information system security goals are achieved.

4. Defines rules for information system security.

5. Provides the resources to develop information system security skills in my organization.

6. Shapes the culture in my firm to protect information.

7. Assigns individuals responsible for managing information system security in my organization.

Mimetic pressure (MIM) (1 = strongly disagree; 5 = strongly agree)

Our main competitors who have adopted information system security practices:

1. Have greatly benefitted.

2. Are favorably perceived by others in the same industry.

3. Are favorably perceived by their suppliers.

4. Are favorably perceived by the customers.

Coercive pressure $(\mathrm{COE})(1=$ strongly disagree; $5=$ strongly agree $)$

Select the best response for each statement.

1. Government requires our organization to secure our information systems. 
2. An industry association encourages our organization to secure our information systems.

3. Competitive conditions require our organization to secure our information systems. 4. Contracts with other businesses require our organization to secure our information systems.

5. Customers expect our organization to secure our information systems.

Normative pressure $($ NOR) $(1=$ strongly disagree; 5 = strongly agree $)$

Select the best response for each statement.

1. I have formal education on information system security.

2. I attend conferences that provide information system security training and education.

3. I receive trade journals that discuss information system security.

4. I see or hear reports about information losses in the media

Absorptive capacity (ABS) ( 1 = strongly disagree; 5 = strongly agree)

1. Our organization has the people with the experience and technical capabilities to implement information system security.

2. Our organization has sufficient resources to implement information system security. 


\title{
Appendix B
}

\author{
Participant Recruitment Letter
}




\section{NOVA SOUTHEASTERN UNIVERSTTY}

Graduate School of Computer and Information Sciences

\section{NSU}

Your organization is invited to participate in a research study on information security implementation. Your organization's participation would involve completing two short surveys on external influences related to information security, and the effect those influences have on senior management.

Dr. Gurvirender Tejay is the principal investigator for this study and an Associate Professor at Nova Southeastern University's Graduate School of Computer Information Sciences. Kevin Barton is the co-investigator and a Doctoral student at Nova Southeastem University's Graduate School of Computer Information Sciences.

Each survey will take less than 15 minutes to complete. One survey is intended for senior management, the other for employees. To participate, please see the attached instructions. There are separate instructions for senior management and employees.

The surveys request demographic information about the organization, but do not collect personal information from participants. The researchers will be able to correlate responses to organizations, but will otherwise not be able to identify participants.

The results from this study will help researchers understand how external influences motivate senior managers to develop and implement information system security programs, and could lead to more effective methods to prepare leaders to protect the critical information resources in their businesses and organizations.

Your organization's participation is important to the success of this study. Participation in the survey will imply consent by your organization and the individuals who participate. Please direct questions regarding this study and this survey to kb149@anova.edu.

Respectfully,

Kevin Barton

Co-Investigator

kb149@nova.edu 


\section{Appendix C}

Participant Instructions for Managers 


\section{NOVA SOUTHEASTERN UNIVERSTTY}

Gradnate School of Computer and Information Sciences

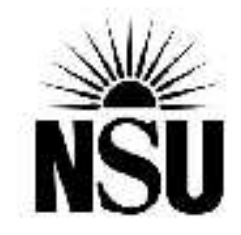

Thank you for participating in this study on information security policy development and implementation. Your participation will involve completing a short survey on external influences related to information system security. The survey is anonymous will take less than 15 minutes to complete.

Completing the survey indicates your consent and voluntary participation in the study.

Please click here to begin the survey.

Kevin Barton is the co-investigator for this study and a Doctoral student at Nova Southeastern University's Graduate School of Computer Information Sciences. Please direct questions to Kevin Barton by email at kb149@nova.edu

Respectfully,

Kevin Barton

Co-Investigator

kb149@nova.edu 


\section{Appendix D}

Participant Instructions for Employees 


\section{NOVA SOUTHEASTERN UNIVERSITY}

Gradnate School of Computer and Information Sciences

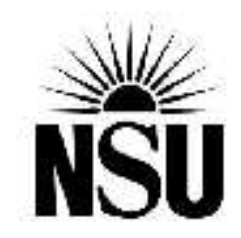

Thank you for participating in this study on information security policy development and implementation. Your participation will involve completing a short survey on management's beliefs about information system security and their participation in information security governance. The survey anonymous will take less than 15 minutes to complete.

Completing the survey indicates your consent and voluntary participation in the study.

Please click here to begin the survey.

Kevin Barton is the co-investigator for this study and a Doctoral student at Nova Southeastern University's Graduate School of Computer Information Sciences. Please direct questions to Kevin Barton by email at kb149@nova.edu

Respectfully,

Kevin Barton

Co-Investigator

kb149@nova.edu 


\section{Reference List}

Ahmad, A., Maynard, S. B., \& Park, S. (2012). Information security strategies: towards an organizational multi-strategy perspective. Journal of Intelligent Manufacturing, 25(2), 357-370. doi:10.1007/s10845-012-0683-0

Allen, J. H. (2005). Governing for enterprise security (pp. i-66). Retrieved from http://www.cert.org/archive/pdf/05tn023.pdf

Anderson, J. M. (2003). Why we need a new definition of information security. Computers \& Security, 22(4), 308-313. doi:10.1016/S0167-4048(03)00407-3

Armstrong, C. P., \& Sambamurthy, V. (1999). Information technology assimilation in firms: The influence of senior leadership and IT infrastructures. Information Systems Research, 10(4), 304-327. doi:10.1287/isre.10.4.304

Baggett, W. O. (2003). Creating a culture of security: The OECD standards for systems security provide internal auditors with the tool for operationalizing tone at the top. Internal Auditor, 60(3), 37-41. Retrieved from http://www.highbeam.com/doc/1G1103194416.html

Bagozzi, R. P. (2011). Measurement and meaning in information systems and organizational research: Methodological and philosophical foundations. MIS Quarterly, 35(2), 261-292. Retrieved from http://misq.org/measurement-andmeaning-in-information-systems-and-organizational-research-methodological-andphilosophical-foundations.html?SID=0pfg7dl6bov314k7h0pfp8mr75

Ball, L., \& Harris, R. (1982). SMIS members: A membership analysis. MIS Quarterly, 6(1), 19-39. Retrieved from http://www.misq.org/contents-06-1/

Bjorck, F. (2004). Institutional theory: A new perspective for research into IS/IT security in organisations. In Proceedings of the 37th Annual Hawaii International Conference on System Sciences (HICSS'04) (pp. 1-5). doi:10.1109/HICSS.2004.1265444

Boss, S. R., Kirsch, L. J., Angermeier, I., Shingler, R. A., \& Boss, R. W. (2009). If someone is watching, I'll do what I'm asked: Mandatoriness, control, and information security. European Journal of Information Systems, 18(2), 151-164. doi:10.1057/ejis.2009.8

Bourgeois, L. J. (1980). Performance and consensus. Strategic Management Journal, l(3), 227-248. doi:10.1002/smj.4250010304 
Bowman, C., \& Kakabadse, A. (1997). Top management ownership of the strategy problem. Long Range Planning, 30(2), 197-150. doi:10.1016/S00246301(96)00112-4

Brancheau, J. C., Janz, B. D., \& Wetherbe, J. C. (1996). Key issues in information systems management: 1994-95 SIM Delphi results. MIS Quarterly, 20(2), 225-243. Retrieved from http://www.misq.org/contents-20-2/

Brancheau, J. C., \& Wetherbe, J. C. (1987). Key issues in information systems management. MIS Quarterly, 11(1), 23-46. Retrieved from http://www.misq.org/contents-11-1/

Bulgurcu, B., Cavusoglu, H., \& Benbasat, I. (2010a). Information security policy compliance: An empirical study of rationality-based beliefs and information security awareness. MIS Quarterly, 34(3), 523-548. Retrieved from http://aisel.aisnet.org/misq/vol34/iss3/9/

Bulgurcu, B., Cavusoglu, H., \& Benbasat, I. (2010b). Quality and fairness of an information security policy as antecedents of employees' security engagement in the workplace: An empirical investigation. In Proceedings of the 43rd Hawaii International Conference on System Sciences (pp. 1-7). Koloa, HI. doi:10.1109/HICSS.2010.300

Caudle, S. L., Gorr, W. L., \& Newcomer, K. E. (1991). Key information systems management issues for the public sector. MIS Quarterly, 15(2), 171-189. Retrieved from http://www.misq.org/contents-15-2/

Cavusoglu, H., Mishra, B., \& Raghunathan, S. (2004). A model for evaluating IT security investments. Communications of the ACM, 47(7), 87-92. doi:10.1145/1005817.1005828

Cavusoglu, H., Raghunathan, S., \& Cavusoglu, H. (2009). Configuration of and interaction between information security technologies: The case of firewalls and intrusion detection systems. Information Systems Research, 20(2), 198-217. doi: $10.1287 /$ isre. 1080.0180

Cenfetelli, R. T., \& Bassellier, G. (2009). Interpretation of formative measurement in information systems research. MIS Quarterly, 33(4), 689-707. Retrieved from http://misq.org/interpretation-of-formative-measurement-in-information-systemsresearch.html?SID=0pfg7dl6bov314k7h0pfp8mr75

Chai, K.-H., Yap, C.-M., \& Wang, X. (2011). Network closure's impact on firms' competitive advantage: The mediating roles of knowledge processes. Journal of Engineering and Technology Management, 28(1-2), 2-22. doi:10.1016/j.jengtecman.2010.12.001 
Chang, A. J.-T., \& Yeh, Q.-J. (2006). On security preparations against possible IS threats across industries. Information Management \& Computer Security, 14(4), 343-360. doi:10.1108/09685220610690817

Chang, S. E., \& Ho, C. B. (2006). Organizational factors to the effectiveness of implementing information security management. Industrial Management \& Data Systems, 106(3), 345-361. doi:10.1108/02635570610653498

Chatterjee, D., Grewal, R., \& Sambamurthy, V. (2002). Shaping up for e-commerce: Institutional enablers of the organizational assimilation of web technologies. MIS Quarterly, 26(2), 65-89. doi:10.2307/4132321

Chen, P., Kataria, G., \& Krishma, R. (2011). Correlated failures, diversification, and information security risk management. MIS Quarterly, 35(2), 397-422. Retrieved from http://misq.org/correlated-failures-diversification-and-information-securityrisk-management.html?SID=0pfg7dl6bov314k7h0pfp8mr75

Chin, W. W. (1998a). Issues and opinion on structural equation modeling. MIS Quarterly, 22(1), vii-xvi.

Chin, W. W. (1998b). The partial least squares approach to structural equation modeling. In G. A. Marcoulides (Ed.), Modern methods for business research (Vol. 41, pp. 295-336). Mahwah, NJ: Lawrence Erlbaum.

Chin, W. W. (2010). How to write up and report PLS analyses. In Handbook of partial least squares (pp. 655-690). Berlin, Heidelberg: Springer. doi:10.1007/978-3-54032827-8_29

Chin, W. W., Marcolin, B. L., \& Newsted, P. R. (2003). A partial least squares latent variable modeling approach for measuring interaction effects: Results from a Monte Carlo simulation study and an electronic-mail emotion/adoption study. Information Systems Research, 14(2), 189-217. doi:10.1287/isre.14.2.189.16018

Cho, J., Park, I., \& Michel, J. W. (2011). How does leadership affect information systems success? The role of transformational leadership. Information \& Management, 48(7), 270-277. doi:10.1016/j.im.2011.07.003

Clark, T. D., Jones, M. C., \& Armstrong, C. P. (2007). The dynamic structure of management support systems. MIS Quarterly, 31(3), 579-615. Retrieved from http://aisel.aisnet.org/cgi/viewcontent.cgi?article=2512\&context=misq

Cohen, J. (1988). Statistical power analysis for the behavioral sciences (2nd ed.). Hillsdale, NJ: Lawrence Erlbaum Associates.

Cohen, J. (1992). A power primer. Psychological Bulletin, 112(1), 155-9. Retrieved from http://www.ncbi.nlm.nih.gov/pubmed/19565683 
Cohen, W. M., \& Levinthal, D. A. (1990). Absorptive capacity: A new perspective on learning and innovation. Administrative Science Quarterly, 35(1), 128. doi:10.2307/2393553

Colbert, A. E., Kristof-Brown, A. L., Bradley, B. H., \& Barrick, M. R. (2008). CEO transformational leadership: The role of goal importance congruence in top management teams. Academy of Management Journal, 51(1), 81-96. doi:10.5465/AMJ.2008.30717744

Corriss, L. (2010). Information security governance: Integrating security into the organizational culture. In Proceedings of the 2010 Workshop on Governance of Technology, Information and Policies - GTIP' 10 (pp. 35-41). New York, New York, USA: ACM Press. doi:10.1145/1920320.1920326

Covin, J. G., Slevin, D. P., \& Schultz, R. L. (1997). Top management decision sharing and adherence to plans. Journal of Business Research, 40(1), 21-36. doi:10.1016/S0148-2963(96)00207-X

Creswell, J. W. (2009). Research design (3rd ed.). Thousand Oaks, CA: Sage Publications, Inc.

Cronbach, L. J. (1951). Coefficient alpha and the internal structure of tests. Psychometrika, 16(3), 297-334. doi:10.1007/BF02310555

D’Arcy, J., Hovav, A., \& Galletta, D. (2009). User awareness of security countermeasures and its impact on information systems misuse: A deterrence approach. Information Systems Research, 20(1), 79-98. doi:10.1287/isre.1070.0160

Da Veiga, A., \& Eloff, J. H. P. (2007). An information security governance framework. Information Systems Management, 24(4), 361-372. doi:10.1080/10580530701586136

Da Veiga, A., \& Eloff, J. H. P. H. P. (2010). A framework and assessment instrument for information security culture. Computers \& Security, 29(2), 196-207. doi:10.1016/j.cose.2009.09.002

Dhillon, G., \& Backhouse, J. (1994). Responsibility analysis: A basis for understanding complex managerial situations. In Proceedings of the International System Dynamics Conference (pp. 70-80). Stirling, Scotland. Retrieved from http://www.systemdynamics.org/conferences/1994/proceed/papers_vol_1/dhillo070. pdf

Dhillon, G., \& Backhouse, J. (1996). Risks in the use of information technology within organizations. International Journal of Information Management, 16(1), 65-74. doi:10.1016/0268-4012(95)00062-3 
Dhillon, G., \& Backhouse, J. (2001). Current directions in IS security research: Towards socio-organizational perspectives. Information Systems Journal, 11, 127-153.

doi:10.1046/j.1365-2575.2001.00099.x

Dhillon, G., Tejay, G. P. S., \& Hong, W. (2007). Identifying governance dimensions to evaluate information systems security in organizations. In Proceedings of the 40th Hawaii International Conference on Systems Sciences (HICSS) (pp. 1-9). doi:10.1109/HICSS.2007.257

Dhillon, G., \& Torkzadeh, G. (2006). Value-focused assessment of information system security in organizations. Information Systems Journal, 16(3), 293-314. doi:10.1111/j.1365-2575.2006.00219.x

Diamantopoulos, A., \& Siguaw, J. a. (2006). Formative versus reflective indicators in organizational measure development: A comparison and empirical illustration. British Journal of Management, 17(4), 263-282. doi:10.1111/j.14678551.2006.00500.x

Diamantopoulos, A., \& Winklhofer, H. M. (2001). Index construction with formative indicators: An alternative to scale development. Journal of Marketing Research, 38(1), 269-277. Retrieved from http://www.jstor.org/stable/1558630

Dickson, G. W., Leitheiser, R. L., Wetherbe, J. C., \& Nechis, M. (1984). Key information systems issues for the 1980's. MIS Quarterly, 8(3), 135-160. Retrieved from http://www.misq.org/contents-08-3/

Dillman, D. A. (1999). Mail and internet surveys: The tailored design method. New York, NY: Wiley Interscience.

DiMaggio, P. J., \& Powell, W. W. (1983). The iron cage revisited: Institutional isomorphism and collective rationality in organizational fields. American Sociological Review, 48(2), 147-159. doi:10.2307/2095101

Dinev, T., Goo, J., Hu, Q., \& Nam, K. (2008). User behaviour towards protective information technologies: The role of national cultural differences. Information Systems Journal, 19(4), 391-412. doi:10.1111/j.1365-2575.2007.00289.x

Doherty, N., \& Fulford, H. (2006). Aligning the information security policy with the strategic information systems plan. Computers \& Security, 25(1), 55-63. doi:10.1016/j.cose.2005.09.009

Doll, W. J. (1985). Avenues for top management involvement in successful MIS development. MIS Quarterly, 9(1), 17-36. Retrieved from http://www.misq.org/contents-09-1/ 
Drevin, L., Kruger, H. A., \& Steyn, T. (2007). Value-focused assessment of ICT security awareness in an academic environment. Computers \& Security, 26(1), 36-43. doi:10.1016/j.cose.2006.10.006

Dutta, A., \& McCrohan, K. (2002). Management's role in information security in a cyber economy. California Management Review, 45(I), 67-87. Retrieved from http://www.jstor.org/stable/41166154

Dutton, J. E., \& Ashford, S. J. (1993). Selling issues to top management. Academy of Management Review, 18(3), 397-428. doi:10.5465/AMR.1993.9309035145

Dutton, J. E., Ashford, S. J., O’Neill, R. M., \& Lawrence, K. A. (2001). Moves that matter: Issue selling and organizational change. Academy of Management Journal, 44(4), 716-736. doi:10.2307/3069412

Eloff, M. M., \& von Solms, S. H. (2000). Information security management: A hierarchical framework for various approaches. Computers \& Security, 19(3), 243 256. doi:10.1016/S0167-4048(00)88613-7

Enns, H. G., Huff, S. L., \& Higgins, C. A. (2003). CIO lateral influence behaviors: Gaining peers' commitment to strategic information systems. MIS Quarterly, 27(1), 155-176. Retrieved from http://misq.org/cio-lateral-influence-behaviors-gainingpeers-commitment-to-strategic-informationsystems.html?SID=0pfg7dl6bov314k7h0pfp8mr75

Erdfelder, E., Faul, F., \& Buchner, A. (1996). GPOWER: A general power analysis program. Behavior Research Methods, Instruments, \& Computers, 28(1), 1-11. doi:10.3758/BF03203630

Evermann, J., \& Tate, M. (2011). Fitting covariance models for theory generation. Information Systems, 12(9), 632-661. Retrieved from http://aisel.aisnet.org/jais/vol12/iss $9 / 2 /$

Farn, K.-J., Lin, S.-K., \& Fung, A. R.-W. (2004). A study on information security management system evaluation: Assets, threat and vulnerability. Computer Standards \& Interfaces, 26(6), 501-513. doi:10.1016/j.csi.2004.03.012

Faul, F., Erdfelder, E., Lang, A.-G., \& Buchner, A. (2007). G*Power 3: A flexible statistical power analysis program for the social, behavioral, and biomedical sciences, 39(2), 175-191. Retrieved from http://link.springer.com/content/pdf/10.3758/BF03193146.pdf

Fornell, C., \& Bookstein, F. L. (1982). Two structural equation models: LISREL and PLS applied to consumer exit-voice theory. Journal of Marketing, 19(4), 440-453. Retrieved from http://www.jstor.org/stable/3151718 
Fornell, C., \& Larcker, D. F. (1981). Evaluating structural equation models with unobservable variables and measurement error. Journal of Marketing Research, 18(1), 39-50. Retrieved from http://www.jstor.org/stable/3151312

Fox, J., Murray, C., \& Warm, A. (2003). Conducting research using web-based questionnaires: Practical, methodological, and ethical considerations. International Journal of Social Research Methodology, 6(2), 167-180. doi:10.1080/13645570210142883

Fung, A. R.-W., Farn, K.-J., \& Lin, A. C. (2003). Paper: A study on the certification of the information security management systems. Computer Standards \& Interfaces, 25(5), 447-461. doi:10.1016/S0920-5489(03)00014-X

Gallén, T. (2009). Top management team composition and views of viable strategies. Team Performance Management, 15(7/8), 326-342. doi:10.1108/13527590911002113

Garrity, J. T. (1963). Top management and computer profits. Harvard Business Review, $41(4), 6-12,172-174$.

Gefen, D., \& Rigdon, E. E. (2011). An update and extension to SEM guidelines for administrative and social science research. MIS Quarterly, 35(2), iii-xiv. Retrieved from http://misq.org/misq/downloads/download/editorial/542/

Gefen, D., Straub, D. W., \& Bourdreau, M.-C. (2000). Structural equation modeling and regression: Guidelines for research practice. Communications of the Association for Information Systems, 4(7), 1-77. Retrieved from http://aisel.aisnet.org/cais/vol4/iss1/7/

Glunk, U., Heijltjes, M. G., \& Olie, R. (2001). Design characteristics and functioning of top management teams in Europe. European Management Journal, 19(3), 291-300. doi:10.1016/S0263-2373(01)00026-3

Goode, S., \& Lacey, D. (2011). Detecting complex account fraud in the enterprise: The role of technical and non-technical controls. Decision Support Systems, 50(4), 702714. doi:10.1016/j.dss.2010.08.018

Goodhue, D. L., Lewis, W., \& Thompson, R. (2006). PLS, small sample size, and statistical power in MIS research. In Proceedings of the 39th Annual Hawaii International Conference on System Sciences (HICSS'06) (Vol. 00, p. 202b-202b). IEEE. doi:10.1109/HICSS.2006.381

Guenzi, P., Georges, L., \& Pardo, C. (2009). The impact of strategic account managers' behaviors on relational outcomes: An empirical study. Industrial Marketing Management, 38(3), 300-311. doi:10.1016/j.indmarman.2007.09.011 
Gupta, A., \& Hammond, R. (2005). Information systems security issues and decisions for small businesses: An empirical examination. Information Management \& Computer Security, 13(4), 297-310. doi:10.1108/09685220510614425

Hair, J. F., Anderson, R. E., \& Tatham, R. L. (1987). Multivariate data analysis. New York, New York, USA: Macmillan.

Hair, J. F., Black, W. C., Babin, B. J., \& Anderson, R. E. (2010). Multivariate data analysis (7th ed.). Upper Saddle River, NJ, USA: Pearson.

Hair, J. F., Ringle, C. M., \& Sarstedt, M. (2011). PLS-SEM: Indeed a silver bullet. The Journal of Marketing Theory and Practice, 19(2), 139-152. doi:10.2753/MTP10696679190202

Hambrick, D. C. (1981). Strategic awareness within top management teams. Strategic Management Journal, 2(3), 263-279. doi:10.1002/smj.4250020305

Hambrick, D. C., \& Mason, P. A. (1984). Upper echelons: The organization as a reflection of its top managers. The Academy of Management Review, 9(2), 193. doi: $10.2307 / 258434$

Harrington, S. J. (1996). The effect of codes of ethics and personal denial of responsibility on computer abuse judgments and intentions. MIS Quarterly, 20(3), 257. doi:10.2307/249656

Harrison, K., \& White, G. (2010). An empirical study on the effectiveness of common security measures. In Proceedings of the 43rd Hawaii International Conference on System Sciences (pp. 1-9). Koloa, HI. doi:10.1109/HICSS.2010.300

Hartog, C., \& Herbert, M. (1986). 1985 opinion survey of MIS managers: Key issues. MIS Quarterly, 10(4), 351-362. Retrieved from http://www.misq.org/contents-10-4/

Herath, T., \& Rao, H. R. (2009a). Encouraging information security behaviors in organizations: Role of penalties, pressures and perceived effectiveness. Decision Support Systems, 47(2), 154-165. doi:10.1016/j.dss.2009.02.005

Herath, T., \& Rao, H. R. (2009b). Protection motivation and deterrence: A framework for security policy compliance in organisations. European Journal of Information Systems, 18(2), 106-125. doi:10.1057/ejis.2009.6

Holgate, J., \& Hardy, C. A. (2012). Information security governance: Investigating diversity in critical infrastructure organizations. In Proceedings of the 25th Bled Conference (pp. 379-393). Bled, Slovakia. Retrieved from https://domino.fov.unimb.si/proceedings.nsf/Proceedings/2247DD9B6FB9504EC1257A2A0030CB05/\$Fil e/P27_Holgate_8-p.pdf 
Hsu, C. W. (2009). Frame misalignment: Interpreting the implementation of information systems security certification in an organization. European Journal of Information Systems, 18(2), 140-150. doi:10.1057/ejis.2009.7

Hsu, C. W., Lee, J.-N., \& Straub, D. W. (2012). Institutional influences on information systems security innovations. Information Systems Research, 23(3-Part-2), 918-939. doi: $10.1287 /$ isre. 1110.0393

Hu, Q., Hart, P. J., \& Cooke, D. (2007). The role of external and internal influences on information systems security: A neo-institutional perspective. The Journal of Strategic Information Systems, 16(2), 153-172. doi:10.1016/j.jsis.2007.05.004

Ifinedo, P. (2012). Understanding information systems security policy compliance: An integration of the theory of planned behavior and the protection motivation theory. Computers \& Security, 31(1), 83-95. doi:10.1016/j.cose.2011.10.007

Information security governance: Guidance for boards of directors and executive management, 2nd ed. (2006) (2nd ed., pp. 1-47). IT Governance Institute. Retrieved from http://www.isaca.org/KnowledgeCenter/Research/ResearchDeliverables/Pages/Information-Security-GovernanceGuidance-for-Boards-of-Directors-and-Executive-Management-2nd-Edition.aspx

Jarvenpaa, S. L., \& Blake, I. (1991). Executive involvement and participation in the management of information technology. MIS Quarterly, 15(2), 205-228. Retrieved from http://www.misq.org/contents-15-2/

Jarvis, C. B., Mackenzie, S. B., \& Podsakoff, P. M. (2003). A critical review of construct indicators and measurement model misspecification in marketing and consumer research. Journal of Consumer Research, 30(2), 199-218. doi:10.1086/376806

Jarvis, C. B., Mackenzie, S. B., \& Podsakoff, P. M. (2012). The negative consequences of measurement model misspecification: A response to Aguirre-Urreta and Marakas. MIS Quarterly, 36(1), 139-146. Retrieved from http://aisel.aisnet.org/cgi/viewcontent.cgi?article=3012\&context=misq

Johnson, A. M. (2009). Business and security executives views of information security investment drivers: Results from a Delphi study. Journal of Information Privacy and Security, 5(1), 3-27.

Johnson, A. M., \& Lederer, A. L. (2010). CEO/CIO mutual understanding, strategic alignment, and the contribution of IS to the organization. Information \& Management, 47(3), 138-149. doi:10.1016/j.im.2010.01.002

Johnston, A. C., \& Warkentin, M. (2010). Fear appeals and information security behaviors: An empirical study. MIS Quarterly, 34(3), 549-566. Retrieved from http://aisel.aisnet.org/misq/vol34/iss3/10/ 
Judge, W. Q., \& Stahl, M. J. (1995). Middle-manager effort in strategy implementation: A multinational perspective. International Business Review, 4(1), 91-111. doi:10.1016/0969-5931(94)00033-I

Kankanhalli, A., Teo, H.-H., Tan, B. C. Y., \& Wei, K.-K. (2003). An integrative study of information systems security effectiveness. International Journal of Information Management, 23(2), 139-154. doi:10.1016/S0268-4012(02)00105-6

Karanja, E. (2013). A comprehensive review of survey-based research in MIS. Journal of Systems and Information Technology, 15(2), 159-188.

doi:10.1108/13287261311328886

Karyda, M., Mitrou, E., \& Quirchmayr, G. (2006). A framework for outsourcing IS/IT security services. Information Management \& Computer Security, 14(5), 402-415. doi:10.1108/09685220610707421

Kearns, G. S., \& Lederer, A. L. (2004). The impact of industry contextual factors on IT focus and the use of IT for competitive advantage. Information \& Management, 41(7), 899-919. doi:10.1016/j.im.2003.08.018

Killmeyer, J. (2006). Information security architecture: An integrated approach to security in the organization (2nd ed.). Boca Raton, FL: Auerbach Publications.

Knapp, K. J., Marshall, T. E., Rainer, R. K., \& Ford, F. N. (2006). Information security: management's effect on culture and policy. Information Management \& Computer Security, 14(1), 24-36. doi:10.1108/09685220610648355

Kock, N. (2010). Using WarpPLS in e-collaboration studies. International Journal of ECollaboration, 6(4), 1-11. doi:10.4018/jec.2010100101

Kock, N. (2012). WarpPLS 3.0 User Manual. Laredo, TX: ScriptWarp Systems. Retrieved from http://www.scriptwarp.com/warppls/UserManual_WarpPLS_V3.pdf

Kock, N. (2013). Easily calculating the GoF fit index with WarpPLS outputs. WarpPLS. Retrieved August 30, 2014, from http://warppls.blogspot.com/2013/01/easilycalculating-gof-fit-index-with.html

Kock, N. (2014). Advanced mediating effects tests, multi-group analyses, and measurement model assessments in PLS-based SEM. International Journal of ECollaboration, 10(1), 1-13. doi:10.4018/ijec.2014010101

Kock, N., \& Lynn, G. S. (2012). Lateral collinearity and misleading results in variancebased SEM: An illustration and recommendations. Journal of the Association for Information Systems, 13(7), 546-580. Retrieved from http://aisel.aisnet.org/jais/vol13/iss7/2/ 
Kotulic, A. G., \& Clark, J. G. (2004). Why there aren't more information security research studies? Information \& Management, 41(5), 597-607.

doi:10.1016/j.im.2003.08.001

Kouki, R., Poulin, D., \& Pellerin, R. (2010). The impact of contextual factors on ERP assimilation: Exploratory findings from a developed and a developing country. Journal of Global Information Technology Management, 13(1), 28-55. Retrieved from http://dl.acs.org.au/index.php/ajis/article/view/525

Kraemer, H. C., \& Thiemann, S. (1987). How many subjects? Statistical power analysis in research. Newberry Park, CA: Sage Publications, Inc.

Kuhn, J. R., \& Sutton, S. G. (2010). Continuous auditing in ERP system environments: The current state and future directions. Journal of Information Systems, 24(1), 91112. doi:10.2308/jis.2010.24.1.91

Kwon, J., \& Johnson, E. M. (2014). Proactive versus reactive security investments in the healthcare sector. MIS Quarterly, 38(2), 451-471. Retrieved from http://misq.org/proactive-versus-reactive-security-investments-in-the-healthcaresector.html?SID=24jjqsu6ft7lh6c5o66mvttks6

Kwon, J., \& Johnson, M. E. (2013). Security practices and regulatory compliance in the healthcare industry. Journal of the American Medical Informatics Association $\square$ : JAMIA, 20(1), 44-51. doi:10.1136/amiajnl-2012-000906

Lane, M., \& Lum, W. H. (2011). Examining client perceptions of partnership quality and its dimensions in an IT outsourcing relationship. Australian Journal of Information Systems, 17(1), 5-34.

Lee, Y., \& Larsen, K. R. (2009). Threat or coping appraisal: Determinants of SMB executives' decision to adopt anti-malware software. European Journal of Information Systems, 18(2), 177-187. doi:10.1057/ejis.2009.11

Liang, H., Saraf, N., Hu, Q., \& Xue, Y. (2007). Assimilation of enterprise systems: The effect of institutional pressures and the mediating role of top management. MIS Quarterly, 31(1), 59-87. Retrieved from http://aisel.aisnet.org/misq/vol31/iss1/6/

Liebenau, J., \& Backhouse, J. (1990). Understanding information: An introduction (pp. i-135). Palgrave Macmillan.

Maassen, G. F. (2002). An international comparison of corporate governance models (3rd ed., pp. 1-227). Amsterdam, NL: Spencer Stuart Executive Search. Retrieved from http://repub.eur.nl/res/pub/8028/Maassen_9789090125916.pdf 
MacCallum, R. C., \& Browne, M. W. (1993). The use of causal indicators in covariance structure models: Some practical issues. Psychological Bulletin, 114(3), 533-541. Retrieved from http://www.ncbi.nlm.nih.gov/pubmed/8272469

Mackenzie, S. B., Podsakoff, P. M., \& Podsakoff, N. P. (2011). Construct measurement and validation procedures in MIS and behavioral research: Integrating new and existing techniques. MIS Quarterly, 35(2), 293-334. Retrieved from http://aisel.aisnet.org/cgi/viewcontent.cgi?article=2956\&context=misq

Marcoulides, G. A., \& Saunders, C. (2006). PLS: A silver bullet? MIS Quarterly, 30(2), iii-ix. Retrieved from http://www.misq.org/misq/downloads/download/editorial/13/

Martins, A., \& Eloff, J. H. P. (2002). Information security culture. In Security in the information society. IFIP/SEC2002 (pp. 203-214). Boston, MA: Kluwer Academic Publishers.

Massetti, B., \& Zmud, R. W. (1996). Measuring the extent of EDI usage in complex organizations: Strategies and illustrative examples. MIS Quarterly, 20(3), 331-346. Retrieved from http://www.misq.org/contents-20-3/

Mathieson, K., Peacock, E., \& Chin, W. W. (2001). Extending the technology acceptance model: The influence of perceived user resources. Database for Advances in Information Systems, 32(3), 86-112. Retrieved from http://www.highbeam.com/doc/1P3-85428323.html

McFadzean, E., Ezingeard, J.-N., \& Birchall, D. (2006). Anchoring information security governance research: Sociological groundings and future directions. Journal of Information System Security, 2(3), 3-48.

McFadzean, E., Ezingeard, J.-N., \& Birchall, D. (2011). Information assurance and corporate strategy: A Delphi study of choices, challenges, and developments for the future. Information Systems Management, 28(2), 102-129.

doi:10.1080/10580530.2011.562127

Meador, C. L., \& Keen, G. W. (1984). Setting priorities for DSS development. MIS Quarterly, 8(2), 117-130. Retrieved from http://www.misq.org/contents-09-2/

Mignerat, M., \& Rivard, S. (2009). Positioning the institutional perspective in information systems research. Journal of Information Technology, 24(4), 369-391. doi:10.1057/jit.2009.13

Mishra, A. N., \& Agarwal, R. (2009). Technological frames, organizational capabilities, and IT use: An empirical investigation of electronic procurement. Information Systems Research, 21(2), 249-270. doi:10.1287/isre.1080.0220 
Moynihan, T. (1990). What chief executives and senior managers want from their IT departments. MIS Quarterly, 14(1), 15-25. doi:10.2307/249303

Nicholson, N., Schuler, R. S., \& Van de Ven, A. H. (Eds.). (1998). The Blackwell encylopedic dictionary of organizational behavior. Malden, MA: Blackwell Publishers Ltd.

Njenga, K., \& Brown, I. (2012). Conceptualising improvisation in information systems security. European Journal of Information Systems, 21(6), 592-607. doi:10.1057/ejis.2012.3

Nunnally, J. C., \& Bernstein, I. H. (1994). Psychometric theory. New York, New York, USA: McGraw Hill.

OECD guidelines for the security of information systems and networks: Towards a culture of security. (2002). Paris, France. Retrieved from http://oe.cd/2002sg

Ohki, E., Harada, Y., Kawaguchi, S., Shiozaki, T., \& Kagaya, T. (2009). Information security governance framework. In Proceedings of the first ACM workshop on Information security governance - WISG '09 (p. 1). New York, New York, USA: ACM Press. doi:10.1145/1655168.1655170

Pahnila, S., Siponen, M. T., \& Mahmood, M. A. (2007). Employees' behavior towards IS security policy compliance. In Proceedings of the 40th Hawaii International Conference on System Sciences (HICSS) (pp. 1-10). USA. doi:10.1109/HICSS.2007.206

Paquette, S., Jaeger, P. T., \& Wilson, S. C. (2010). Identifying the security risks associated with governmental use of cloud computing. Government Information Quarterly, 27(3), 245-253. doi:10.1016/j.giq.2010.01.002

Patnayakuni, R., \& Patnayakuni, N. (2014). Information security in value chains: A governance perspective. In Proceedings of the 20th Americas Conference on Information Systems (pp. 1-10). Savannah, GA. Retrieved from http://aisel.aisnet.org/cgi/viewcontent.cgi?article=1161\&context=amcis 2014

Petter, S., Rai, A., \& Straub, D. W. (2012). The critical importance of construct measurement specification: A response to Aguirre-Urreta and Marakas. MIS Quarterly, 36(1), 147-155. Retrieved from http://aisel.aisnet.org/cgi/viewcontent.cgi?article=3013\&context=misq

Petter, S., Straub, D. W., \& Rai, A. (2007). Specifying formative constructs in information systems research. MIS Quarterly, 31(4), 623-656. Retrieved from http://aisel.aisnet.org/misq/vol31/iss4/2/ 
Pinsonneault, A., \& Kraemer, K. L. (1993). Survey research methodology in management information systems: An assessment. Journal of Management Information Systems, 10(2), 75-105. Retrieved from

http://search.proquest.com.ezproxylocal.library.nova.edu/docview/218943275?acco untid $=6579$

Podsakoff, P. M., MacKenzie, S. B., Lee, J. Y., \& Podsakoff, N. P. (2003). Common method biases in behavioral research: A critical review of the literature and recommended remedies. The Journal of Applied Psychology, 88(5), 879-903. doi:10.1037/0021-9010.88.5.879

Podsakoff, P. M., \& Organ, D. W. (1986). Self-Reports in Organizational Research: Problems and Prospects. Journal of Management, 12(4), 531-544. doi:10.1177/014920638601200408

Puhakainen, P. (2006). A design theory for information security awareness. Oulu, Finland: Oulu University Press. Retrieved from herkules.oulu.fi/isbn9514281144/isbn9514281144.pdf

Puhakainen, P., \& Siponen, M. T. (2010). Improving employees' compliance through information systems security training: An action research study. MIS Quarterly, 34(4), 757-778. Retrieved from http://aisel.aisnet.org/misq/vol34/iss4/9/

Purvis, R. L., Sambamurthy, V., \& Zmud, R. W. (2001). The assimilation of knowledge platforms in organizations: An empirical investigation. Organization Science, 12(2), 117-135. Retrieved from http://orgsci.journal.informs.org/

Ringle, C. M., Sarstedt, M., \& Straub, D. W. (2012). A critical look at the use of PLSSEM in MIS Quarterly. MIS Quarterly, 36(1), iii-xiv. Retrieved from http://aisel.aisnet.org/misq/vol36/iss1/2/

Roberts, N., Galluch, P. S., Dinger, M., \& Grover, V. (2012). Absorptive capacity and information systems research: Review, synthesis, and directions for future research. MIS Quarterly, 36(2), 625-648. Retrieved from http://aisel.aisnet.org/misq/vol36/iss2/15/

Salkind, N. J. (2009). Exploring research (7th ed.). Upper Saddle River, NJ, USA: Pearson Education, Inc.

Sánchez, L. E., Parra, A. S.-O., Rosado, D. G., \& Piattini, M. (2009). Managing security and its maturity in small and medium-sized enterprises. Journal of Computer Science, 15(15), 3038-3058. doi:10.3217/jucs-015-15-3038

Sarstedt, M., Henseler, J., \& Ringle, C. M. (2011). Multigroup analysis in partial least squares (PLS) path modeling: Alternative methods and empirical results. In 
Advances in International Marketing (Vol. 22, pp. 195-218). Bingley, UK: Emerald Group Publishing Limited. doi:10.1108/S1474-7979(2011)0000022012

Schein, E. H. (1990). Organizational culture. American Psychologist, 45(2), 109-119. doi:10.1016/j.sapharm.2010.06.002

Seeholzer, R. V. (2012). Information security strategy: In search of a role. In Proceedings of the 2012 Americas Conference on Information Systems (AMCIS 2012) (pp. 1-18). Seattle, WA. Retrieved from http://aisel.aisnet.org/cgi/viewcontent.cgi?article=1194\&context=amcis 2012

Sekaran, U., \& Bougie, R. (2010). Research methods for business (5th ed.). West Sussex, UK: Wiley \& Sons Ltd.

Shmueli, G., \& Koppius, O. R. (2011). Predictive analytics in information systems research. MIS Quarterly, 35(3), 553-572. Retrieved from http://aisel.aisnet.org/misq/vol36/iss1/2/

Siponen, M. T., Pahnila, S., \& Mahmood, M. A. (2007). Employees' adherence to information security policies: An empirical study. In In the Proceedins of IFIP SEC 2007 (pp. 133-144). Sandton, Gauteng, South Africa. doi:10.1007/978-0-38772367-9_12

Siponen, M. T., Pahnila, S., \& Mahmood, M. A. (2010). Compliance with information security policies: An empirical investigation. Computer, 43(2), 64-71. doi:10.1109/MC.2010.35

Siponen, M. T., \& Vance, A. (2010). Nuetralization: New insights into the problem of employee information systems security policy violations. MIS Quarterly, 34(3), 487-502. Retrieved from http://aisel.aisnet.org/misq/vol34/iss3/7/

Siponen, M. T., \& Willison, R. (2005). A critical assessment of IS security research between 1990-2004. In European Conference on Information Systems - ECIS (pp. 1551-1559). St. Gallen, Switzerland. Retrieved from http://aisel.aisnet.org/ecis2007/190/

Sivo, S. A., Saunders, C., Chang, Q., \& Jiang, J. J. (2006). How low should you go? Low response rates and the validity of inference in IS questionnaire research. Journal of the Association for Information Systems, 7(6), 351-414. Retrieved from http://aisel.aisnet.org/jais/vol7/iss6/

Smith, S., \& Jamieson, R. (2006). Determining key factors in E-government information system security. Information Systems Management, 23(2), 23-32.

doi:10.1201/1078.10580530/45925.23.2.20060301/92671.4 
Smith, S., Winchester, D., Bunker, D., \& Jamieson, R. (2010). Circuits of power: A study of mandated compliance to an information systems security de jure standard in a government organization. MIS Quarterly, 34(3), 463-486. Retrieved from http://aisel.aisnet.org/misq/vol34/iss3/6/

Son, J.-Y. (2011). Out of fear or desire? Toward a better understanding of employees' motivation to follow IS security policies. Information \& Management, 48(7), 296302. doi:10.1016/j.im.2011.07.002

Spears, J. L., \& Barki, H. (2010). User participation in information systems security risk management. MIS Quarterly, 34(3), 503-522. Retrieved from http://misq.org/userparticipation-in-information-systems-security-risk-management-1.html

Straub, D. W. (1989). Validating instruments in MIS research. MIS Quarterly, 13(2), 103-118. Retrieved from http://aisel.aisnet.org/cgi/viewcontent.cgi?article=2100\&context=misq

Straub, D. W., \& Nance, W. D. (1990). Discovering and disciplining computer abuse in organizations: A field study. MIS Quarterly, 14(1), 45-60. doi:10.2307/249307

Sue, V. M., \& Ritter, L. A. (2012). Conducting online surveys (2nd ed.). Thousand Oaks, CA: SAGE Publications Ltd.

Sun, L., Srivastava, R. P., \& Mock, T. J. (2006). An information systems security risk assessment model under the Dempster-Shafer theory of belief functions. Journal of Management Information Systems, 22(4), 109-142. doi:10.1.1.88.7729

Swanson, E. B., \& Ramiller, N. C. (2004). Innovating mindfully with information technology. MIS Quarterly, 28(4), 553-583. Retrieved from http://aisel.aisnet.org/cgi/viewcontent.cgi?article=2710\&context=misq

Tejay, G. P. S., \& Barton, K. A. (2013). Information system security commitment: A pilot study of external influences on senior management. In 2013 46th Hawaii International Conference on System Sciences (pp. 3028-3037). Wailea, HI. doi:10.1109/HICSS.2013.273

Tenenhaus, M., Vinzi, V. E., Chatelin, Y.-M., \& Lauro, C. (2005). PLS path modeling. Computational Statistics \& Data Analysis, 48(1), 159-205. doi:10.1016/j.csda.2004.03.005

Teo, H.-H., Wei, K. K., \& Benbasat, I. (2003). Predicting intention to adopt interorganizational linkages: An institutional perspective. MIS Quarterly, 27(1), 1949. Retrieved from http://aisel.aisnet.org/cgi/viewcontent.cgi?article=2649\&context=misq 
Thong, J. Y. L. (1999). An integrated model of information systems adoption in small businesses. Journal of Management Information Systems, 15(4), 187-215. Retrieved from http://ssrn.com/abstract=1977980

Vanlommel, E., \& De Brabander, B. (1975). The organization of electronic data processing (EDP) activities and computer use. The Journa of Business, 48(3), 391410. Retrieved from http://www.jstor.org/stable/2352232

Von Solms, R., \& von Solms, B. (2006a). Information security governance: A model based on the direct-control cycle. Computers \& Security, 25(6), 408-412. doi:10.1016/j.cose.2006.07.005

Von Solms, R., \& von Solms, B. (2006b). Information security governance: Due care. Computers \& Security, 25(7), 494-497. doi:10.1016/j.cose.2006.08.013

Vroom, C., \& von Solms, R. (2002). A practical approach to information security awareness in the organization. In M. A. Ghonaimy, M. T. El-Hadidi, \& H. K. Aslan (Eds.), Security in the Information Society (pp. 19-37). Springer US. doi:10.1007/978-0-387-35586-3_2

Wang, H., Xu, H., Lu, B., \& Shen, Z. (2009). Research on security architecture for defending insider threat. In Proceedings of the Fifth International Conference on Information Assurance and Security (pp. 30-33). Xi' An, China. doi:10.1109/IAS.2009.53

Watson, R. T. (1990). Influences on the IS Manager's perceptions of key issues: Information scanning and the relationship with the CEO. MIS Quarterly, 14(2), 217231. doi: $10.2307 / 248780$

Werlinger, R., Hawkey, K., \& Beznosov, K. (2009). An integrated view of human, organizational, and technological challenges of IT security management. Information Management \& Computer Security, 17(1), 4-19. doi:10.1108/09685220910944722

Westland, C. J. (2010). Lower bounds on sample size in structural equation modeling. Electronic Commerce Research and Applications, 9(6), 476-487. doi:10.1016/j.elerap.2010.07.003

Westley, F. R. (1990). Middle managers and strategy: Microdynamics of inclusion. Strategic Management Journal, 11(5), 337-351. doi:10.1002/smj.4250110502

Wetzels, M., Odekerken-Schroder, G., \& van Oppen, C. (2009). Using PLS path modeling for assessing hierarchical construct models: Guidelines and empirical illustration. MIS Quarterly, 33(1), 177-195. Retrieved from http://misq.org/usingpls-path-modeling-for-assessing-hierarchial-construct-models-guidelines-andimpirical-illustration.html?SID=24jjqsu6ft7lh6c5o66mvttks6 
Williams, L. J., Edwards, J. R., \& Vandenberg, R. J. (2003). Recent advances in causal modeling methods for organizational and management research. Journal of Management, 29(6), 903-936. doi:10.1016/S0149-2063(03)00084-9

Wooldridge, B., \& Floyd, S. W. (1990). The strategy process, middle management involvement, and organizational performance. Strategic Management Journal, 11(3), 231-241. doi:10.1002/smj.4250110305

Xue, Y., Liang, H., \& Wu, L. (2010). Punishment, justice, and compliance in mandatory IT settings. Information Systems Research, 22(2), 400-414. doi:10.1287/isre.1090.0266

Yeh, Q.-J., \& Chang, A. J.-T. (2007). Threats and countermeasures for information system security: A cross-industry study. Information \& Management, 44(5), 480491. doi:10.1016/j.im.2007.05.003 